\title{
Experimental Study on Dry Friction Damping Characteristics of the Steam Turbine Blade Material with Nonconforming Contacts
}

\author{
Jun Wu, ${ }^{1}$ Ruishan Yuan, ${ }^{1}$ Zhenwu He, ${ }^{1}$ Di Zhang, ${ }^{2}$ and Yonghui Xie ${ }^{1}$ \\ ${ }^{1}$ School of Energy and Power Engineering, Xian Jiaotong University, Xi'an, Shaanxi 710049, China \\ ${ }^{2}$ Key Laboratory of Thermal Fluid Science and Engineering, Ministry of Education, School of Energy and Power Engineering, \\ Xian Jiaotong University, Xian, Shaanxi 710049, China
}

Correspondence should be addressed to Yonghui Xie; yhxie@mail.xjtu.edu.cn

Received 30 April 2014; Accepted 7 December 2014

Academic Editor: Chi-Wai Chow

Copyright ( $\odot 2015$ Jun Wu et al. This is an open access article distributed under the Creative Commons Attribution License, which permits unrestricted use, distribution, and reproduction in any medium, provided the original work is properly cited.

\begin{abstract}
An experiment system has been established to study the dry friction damping dynamic characteristics of the steam turbine blade material 1Cr13. The friction dynamic characteristics of the specimens with nonconforming contact surfaces are measured under different parameters. The experiment results are compared with that of the macroslip hysteresis model and the Mindlin microslip friction model in detail. The results show that the experimental result of the tangential contact stiffness is in good agreement with that of the theory result based on the fractal theory and the Hertz contact theory by Jiang et al., 2009. The dimensionless equivalent stiffness and equivalent damping obtained by the macroslip hysteresis model agree well with the experimental results when relative motion is relatively large. However, the results of the macroslip hysteresis model differ a lot from the experimental results when relative motion is relatively small. Compared with the macroslip hysteresis model, the Mindlin microslip friction model can predict the dimensionless equivalent stiffness and equivalent damping accurately during the whole measurement range. The linear regularities of dimensionless equivalent stiffness and equivalent damping are obtained, which decrease the difficulty of building the vibration analysis model of the blade with sufficient accuracy.
\end{abstract}

\section{Introduction}

As the steam turbine blade works in the environment of high temperature and high pressure, not only the relatively large centrifugal force but also the exciting force acts on the blade. The blade will be resonant as the frequency of the exciting force is very close to the natural frequency. And then the vibration amplitude will increase suddenly which is the main cause for large dynamic stresses of the blade [1]. The main reason for turbine blade failure can be attributed to high cycle fatigue caused by large dynamic stresses when resonance happens. In order to improve the safety and reliability of the blade, the vibration stress can be decreased by adding damping to the blade without changing the working conditions of the system and the flow size [2]. Dry friction damping structures have been widely used in the structural design of the blade to decrease the vibration stress effectively, such as friction dampers, snubbers, lacing wire, and shrouds.
The friction between the contact surfaces is the key point of the vibration energy dissipation of the blade with dry friction damping structures. In order to reveal the dry friction damping vibration characteristics of the steam turbine blade, it is very important to carry out in-depth study on the friction damping dynamic characteristics between the contact surfaces. Because of the strong nonlinearity of the friction phenomenon, there are a number of theory models for the description of the friction damping characteristics between the dry friction contact surfaces. In the theory models, the tangential contact stiffness, the equivalent stiffness, and the equivalent damping coefficient between the contact surfaces under the effect of harmonic exciting loads are the critical parameters that have important effects on stick-slip motion states and the damping effects of the contact surfaces. In order to investigate these critical parameters, the hysteresis curves which characterized the friction damping dynamic characteristics between the contact surfaces were analyzed by experimental methods at home and abroad [3]. Mindlin et 
al. investigated the hysteresis curves for lenses with convex surfaces by experimental tests. The value of energy dissipation was not consistent with the theories developed by Mindlin et al. [4]. Goodman and Brown further measured the hysteresis curves at the contacts of a sphere oscillating between two parallel flat plates. The value of energy dissipation was consistent with the Mindlin theory when the displacement of relative motion was large than the half of the critical displacement [5]. Liang and Feeny obtained the hysteresis curves and the tangential contact stiffness of the contact surfaces by experimental tests. However, the friction contact stiffness and the system stiffness were not separated during the tests $[6,7]$. Filippi et al. measured the hysteresis curves of the contact surfaces by a variable cross-section beam. The friction coefficient and the tangential contact stiffness were obtained. The errors of the test system were analyzed in detail to ensure the accuracy of the measurements [8]. The hysteresis curves of vehicle-used metallic material were tested by Lin et al. The dimensionless equivalent stiffness and damping coefficients were in good agreement with the results calculated by finite element numerical analysis [9]. Mindlin et al. investigated the hysteresis curves of contact surfaces under different normal forces and exciting forces by experiments. The changing pattern of the tangential contact stiffness on the normal forces was analyzed and the numerical method for calculating the contact stiffness was verified [4].

It is observed from the above research review that most researches put emphasis on the materials of ordinary steel and aluminum alloy. The alloy steel materials of steam turbine blades are seldom investigated. The parameter types during current researches are also very limited. Some parameters that have important effects on the vibration characteristics of blades are less studied, such as the contact radius and the exciting frequency. The contact radius is one of the key parameters for the optimization of friction damping structures. And the exciting force applied to the blade is composed by several harmonic forces with different frequencies. In this paper, the dry friction damping dynamic characteristics of steam turbine blade materials with nonconforming contacts are studied in detail. Based on the existing standard vibration isolation platform in the lab, a rig for the test of dry friction damping dynamic characteristics of steam turbine blade metallic materials with nonconforming contacts is built. The metallic material $1 \mathrm{Cr} 13$ which has been widely used in steam turbine blades is measured. The changing patterns of the friction damping dynamic characteristics of contact surfaces on different parameters are investigated in detail. The experiment results are compared with that of the relevant theory models which provide a foundation for building the reliable vibration characteristics analysis model of steam turbine blade with dry friction damping structures.

\section{The Friction Contact Theory Model}

It is almost impossible to use a general mathematic model to characterize the physical characteristics of friction contacts because of the inherent complex nonlinearity of the friction phenomenon [10]. There are many dry friction contact models proposed by researchers at home and abroad. The macroslip hysteresis model has been widely applied to the design and analysis of blades with dry friction damping structures for it has simple expression and can reflect the basic friction damping characteristics of contact surfaces [11]. By comparing with the macroslip friction model, the friction damping characteristics of contact surfaces can be descripted more accurate under large normal forces and small displacements of relative motion by microslip friction model that can take the effect of the local slip of contact surfaces on the friction damping characteristics.

In order to compare with the experimental results, the macroslip hysteresis model and the Mindlin microslip model are introduced separately as follows.

The vibration attenuation effect can be analyzed quantitatively by macroslip hysteresis model for the contact stiffness of the contact surfaces is considered in this model. As shown in Figure 1, the changing pattern of the friction force $f$ is

$$
f(u)= \begin{cases}\mu N+K_{d}(u-A) & 0 \leq \theta<\theta^{*} \\ -\mu N & \theta^{*} \leq \theta<\pi \\ -\mu N+K_{d}(u-A) & \pi \leq \theta<\pi+\theta^{*} \\ \mu N & \pi+\theta^{*} \leq \theta<2 \pi\end{cases}
$$

where $f$-friction force/N; $\mu$-dynamic friction coefficient; $N$-normal force of the contact surfaces/ $\mathrm{N} ; x-$ displacement of relative motion between contact surfaces $/ \mathrm{m}$; $K_{d}$-tangential contact stiffness $/ \mathrm{N} \mathrm{m}^{-1} ; \theta$-phase angle $/ \mathrm{rad}$ (the motion state of the contact surfaces turns from stick to slip as the $\theta$ equals to $\theta^{*}$ ); and $A$-displacement amplitude of the relative motion $/ \mathrm{m}$.

In consideration of the elastic contact deformation of contact surfaces, a microslip model for describing the friction damping characteristics of contact surfaces was proposed by Koh et al. [12]. As shown in Figure 2, the changing pattern of the friction force $f$ is

$$
\begin{aligned}
& f(u) \\
& \left\{\begin{array}{c}
\mu N-2 \mu N\left\{1-\left(\frac{1}{2}\right)^{3 / 2}\left[1+\frac{2}{3 A_{0}}\right.\right. \\
\left.\left.\cdot\left(u-A+\frac{3}{2} A_{0}\right)\right]^{3 / 2}\right\} \\
-\mu N \quad \theta^{*} \leq \theta<\pi \\
-\mu N+2 \mu N\left\{1-\left(\frac{1}{2}\right)^{3 / 2}\left[1-\frac{2}{3 A_{0}}\right.\right. \\
\left.\left.\quad \cdot\left(u+A-\frac{3}{2} A_{0}\right)\right]^{3 / 2}\right\} \\
\pi \leq \theta<\pi+\theta^{*} \\
\pi+\theta^{*} \leq \theta<2 \pi,
\end{array}\right.
\end{aligned}
$$

where $f$-friction force/ $\mathrm{N} ; f^{*}$-the amplitude of the friction force during microslip/N;A-displacement amplitude of the relative motion $\mu \mathrm{m} ; A_{0}-$ critical displacement amplitude 


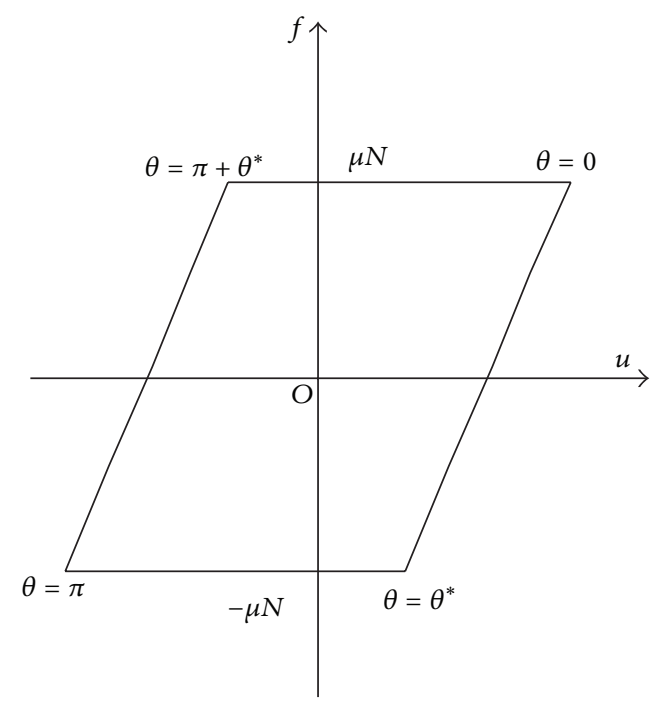

FIGURE 1: Macroslip hysteresis model [17].

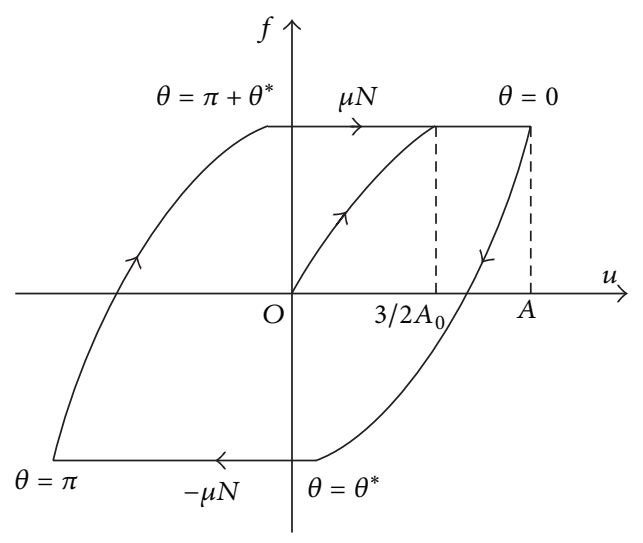

Figure 2: Mindlin microslip model [12].

of the relative motion $/ \mu \mathrm{m}$; $u$-displacement of the relative motion $/ \mu \mathrm{m} ; \mu-$ dynamic friction coefficient; and $N-$ normal forces of contact surfaces/ $\mathrm{N}$.

\section{Experimental Scheme and Test Devices}

3.1. Experimental Objects. It is known that contact problems can be divided into two types: one is conforming contact and the other is nonconforming contact. The conforming contact refers to the behavior that two bodies fit closely with each other at the contact surface when there is no deformation, and the contact stress tends to infinity at the endpoint of the contact region where the stress singularity can be found. The nonconforming contact refers to the behavior that two bodies contact with each other only at a point or along line. The contact region expands as the contact load increases. The stress is zero at the endpoint of the contact region [13]. The contact state will turn from surface contact to point contact easily on account of the relative motion of the contact surfaces for the conforming contact. Therefore, the performance of the friction damping structure will be severely affected for it is very difficult to predict the contact state accurately under the working conditions. Unlike the conforming contact, the contact state of the contact surfaces will not change immediately for the inherent contact characteristics of the nonconforming contact. As a result, the dry friction damping structures with nonconforming contact are widely used in blades for it will keep good performance under the working conditions [14]. As a result, the nonconforming spherical surface to plane surface contact of the steam turbine blade material is investigated in this paper. The movement friction specimen with a plane contact surface is shown in the left side of Figure 3. The stationary friction specimen with a spherical contact surface is shown in the right side of Figure 3.

3.2. Experimental Scheme. The purpose of the experiment is to measure the hysteresis curves of the tangential friction force versus the displacement of relative motion attributed to the relative motion with small amplitude between the dry friction contact surfaces. In order to minimize the experimental errors, there are a couple of things to be aware of during the design process. The motion of the contact surfaces should be limited to only one direction. In order to minimize the variation of the normal force, the mass and the stiffness along the normal direction of the contact surface of the stationary friction specimen should be small enough to be ignored. The contact surface should not rotate during the relative motion. The friction contact specimens should be easy to replace. In the experiment, a variable crosssection beam with fixed ends is excited by an electromagnetic vibration exciter. The moveable friction specimen fixed at the center position of the beam moves back and forth with the center section of the beam in the vertical direction. The stationary friction specimen is fixed at a stationary support device. In addition, the stationary support device is pressed to the piezoelectric force sensors fixed on the basis by the similar spherical hinge joints of two metal rods perpendicular with each other. The normal force which is applied by the calibrated dead weight is transferred to the contact surface by nylon cord and the pulley mechanism. A mirror surface with 45 degrees is applied to reflect the laser from the laser Doppler vibrometer to the position close to the contact region on the moveable friction specimen. The displacement of the relative motion and the tangential friction force are measured by the laser Doppler vibrometer and the piezoelectric force sensor, respectively.

3.3. Experimental System and Devices. According to the experimental scheme above, a rig for the test of dry friction damping dynamic characteristics of metallic materials is built. The experimental test system is shown in Figure 4. The rig consists of beam and the corresponding fixing device, the stationary friction specimen support device, the device for applying the normal force to the friction contact surface, the device for applying the exciting force, the friction contact specimen, and the measuring device in the experiment.

3.3.1. The Variable Cross-Section Beam and the Corresponding Fixing Device. The purpose for the variable cross-section 


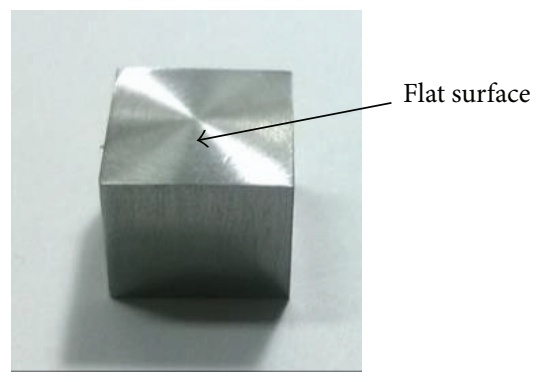

(a)

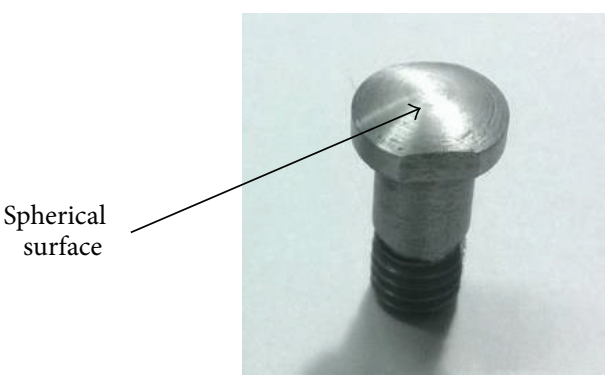

(b)

FIGURE 3: Experiment friction specimens ((a) moveable friction specimen, (b) stationary friction specimen).

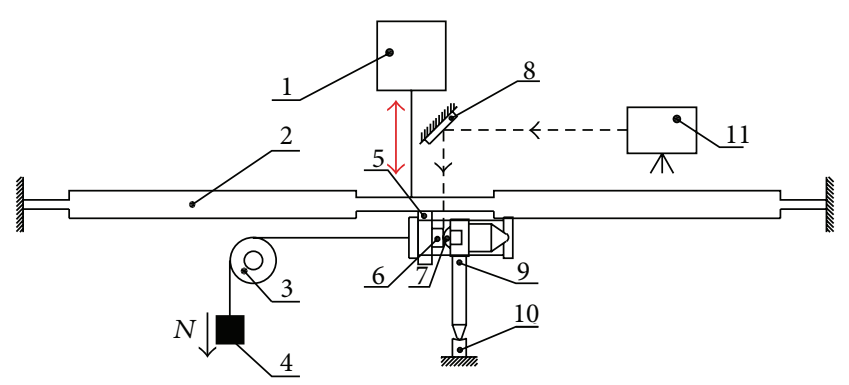

FIGURE 4: Schematic diagram of the test system: (1) vibration generator, (2) variable cross-section beam, (3) pulley, (4) calibrated dead weights, (5) link block of the moveable friction specimen, (6) moveable friction specimen, (7) stationary friction specimen, (8) mirror, (9) stationary support mechanism, (10) dynamic force sensor, and (11) laser head.

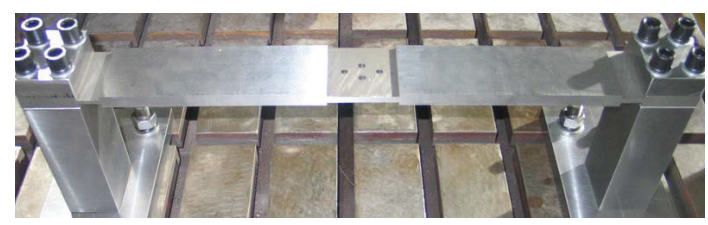

FIGURE 5: The photo of the variable cross-section beam and the corresponding fixing device.

beam and the corresponding fixing device is to fix the beam to the vibration isolation platform. As is shown in Figure 5, both the left end and the right end of the beam are fixed between the support foundation and the lock block. The bottom of the support foundation is fixed to the platform.

In order to ensure the moveable friction specimen vibrates only in the transverse direction of the beam, the natural frequencies of the second bending vibration mode $\left(\omega_{2}\right)$ and the first torsion vibration mode $\left(\omega_{3}\right)$ to that of the first bending vibration mode $\left(\omega_{1}\right)$ should be large enough according to the relevant knowledge of vibration theory. Based on the initial design values, the physical dimensions of the variable cross-section beam are optimized to satisfy the request of the frequency ratio. Figure 6 shows the physical dimensions of the variable cross-section beam, where $\mathbf{L}$ refers to the length of the beam, $\mathbf{W}$ refers to the width of the beam, $\mathrm{H}$ refers to the height of the beam, a refers to the length of the

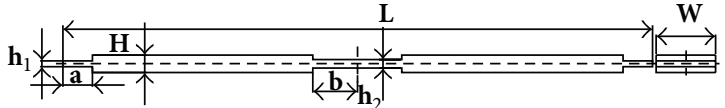

Figure 6: Physical dimensions of the variable cross-section beam.

variable cross-section part at the ends of the beam, $\mathbf{h}_{1}$ refers to the height of the variable cross-section part at the ends of the beam, $\mathbf{2} \mathbf{b}$ refers to the length of the variable cross-section part at the center of the beam, and $\mathbf{h}_{2}$ refers to the height of the variable cross-section part at the center of the beam.

By optimization analysis, the final values of the physical dimensions and the frequency ratios of the variable crosssection beam are obtained: $\mathbf{L}, \mathbf{W}$, and $\mathbf{H}$ are $480 \mathrm{~mm}, 65 \mathrm{~mm}$, and $12 \mathrm{~mm}$; $\mathbf{a}, \mathbf{h}_{1}, \mathbf{b}$, and $\mathbf{h}_{2}$ are $20 \mathrm{~mm}, 4 \mathrm{~mm}, 30 \mathrm{~mm}$, and $6 \mathrm{~mm} ; \boldsymbol{\omega}_{1}, \boldsymbol{\omega}_{2}$, and $\boldsymbol{\omega}_{3}$ are $110.88 \mathrm{~Hz}, 515.32 \mathrm{~Hz}$, and $924.76 \mathrm{~Hz}$; and $\omega_{2} / \omega_{1}, \omega_{3} / \omega_{1}$ are $4.65,8.34$, respectively. As a result, the negative effect of high order vibration mode on the measurement is reduced and the reliability of the experiment is improved.

3.3.2. The Stationary Friction Specimen Support Device. The support device is designed to fix the stationary friction specimen during the tests, as is shown in Figure 7. The stationary friction specimen is installed at the corner of the fixed support block and remains still in the plane of the metal rods. The contact surface moves in the plane of the metal rods axis. Because of the effect of the similar spherical hinges between the metal rod and the piezoelectric force sensor, the stiffness of the contact surface in the normal direction of the support device can be ignored. Therefore, the contact stiffness of the friction specimen is separated with the system stiffness, which improves the measurement accuracy of the friction characteristics. The tangential friction force of the contact surface is measured by the piezoelectric force sensor which is fixed in the vertical direction. Moreover, a tensile force is applied to the stationary friction specimen by a mechanism for applying the preload to keep it still in the plane of the metal rods axis.

3.3.3. The Device for Applying the Normal Force to the Friction Contact Surface. The normal force is applied to the friction contact surface by the device described in Figure 8 . 


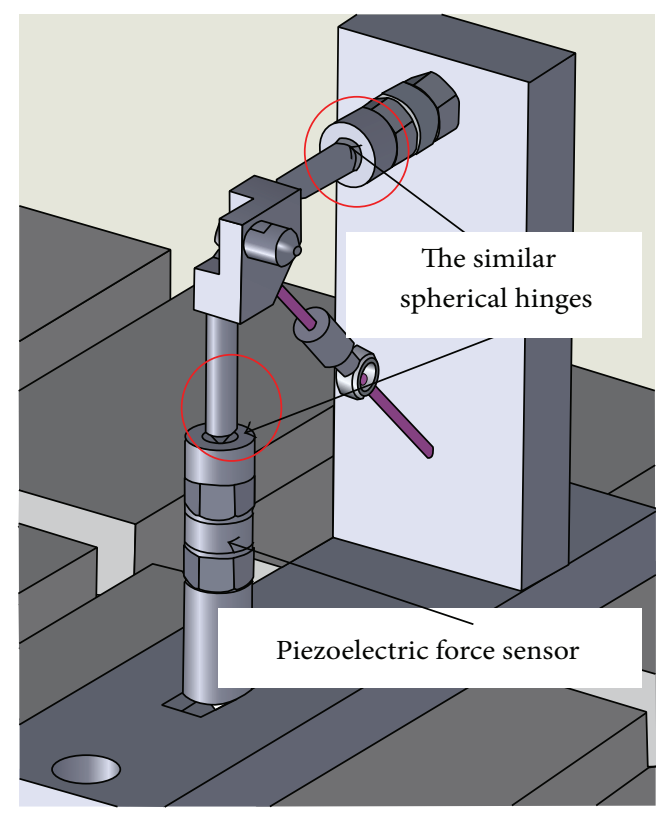

(a)

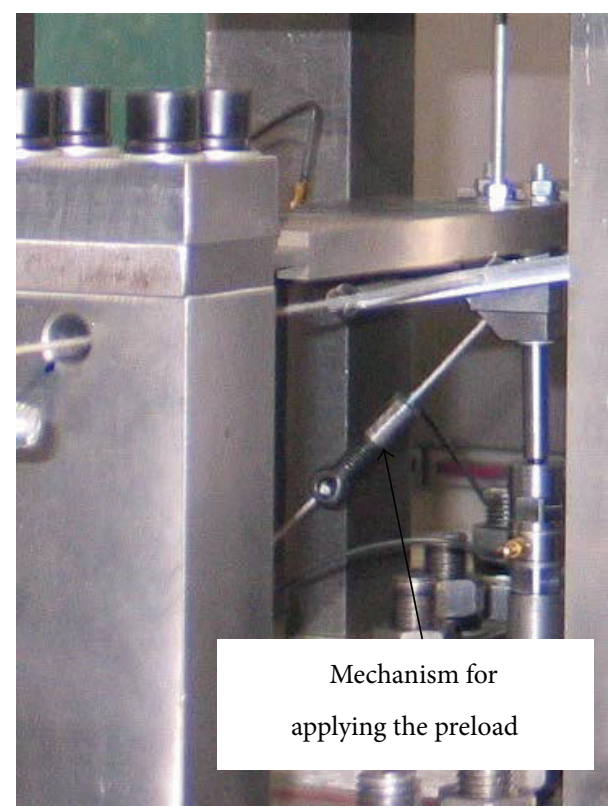

(b)

FigurE 7: The stationary friction specimen support device ((a) 3D model, (b) the photo).

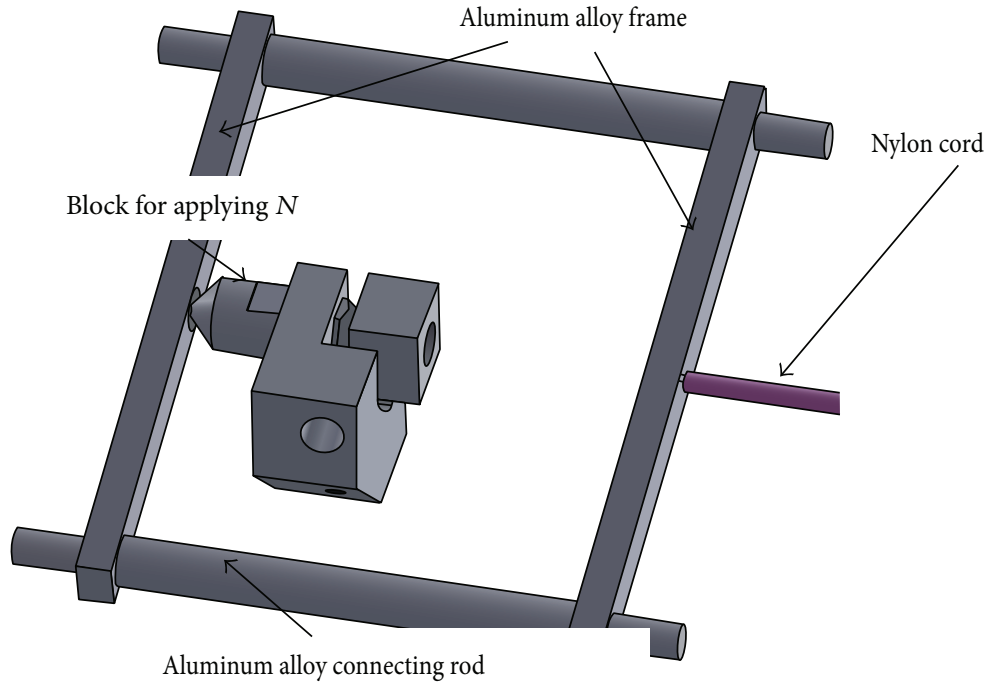

(a)

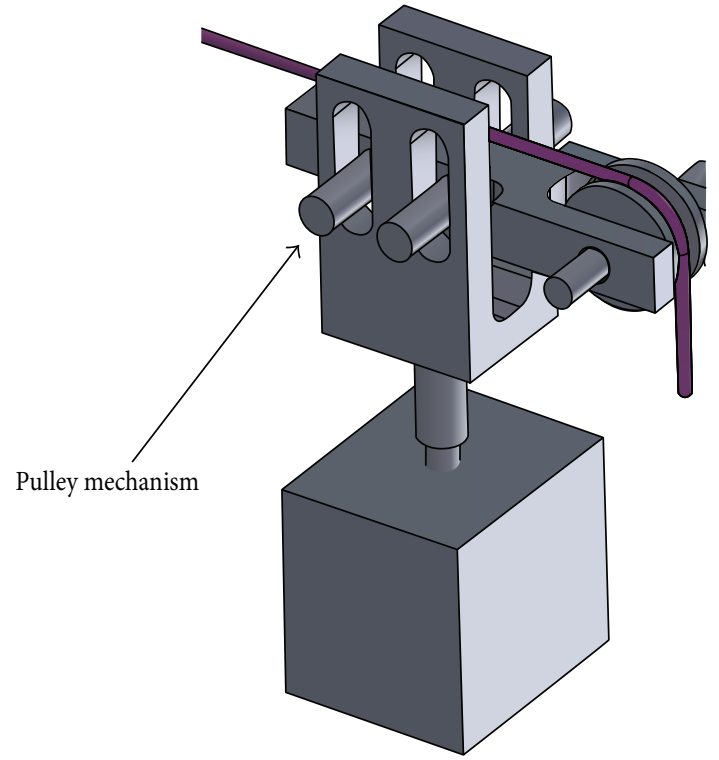

(b)

FIGURE 8: The device for applying normal force ((a) aluminum alloy frame, (b) pulley mechanism).

The device consists of the block for applying the normal force, aluminum alloy frame, aluminum alloy connecting rod, nylon cord, pulley mechanism, and the calibrated dead weight. In order to decrease the variation of the normal force attributed to the movement of the friction specimen in the normal direction, the aluminum alloy with small density is applied for the frame and the connecting rod to reduce the structure mass in the normal direction of the contact surface. As is shown in Figure 8, the aluminum alloy frame behind the stationary friction specimen is connected to the frame in the front side by two aluminum alloy connecting rods. The frame in front of the stationary friction specimen is connected to the pulley mechanism by the nylon cord. The calibrated dead weight is connected to the pulley mechanism by the nylon cord. And the normal force of the contact surface is applied and adjusted by the calibrated dead weight. As is shown in the right side of Figure 8, the supporting frame of the pulley mechanism consists of the magnetic base, connecting rod, 


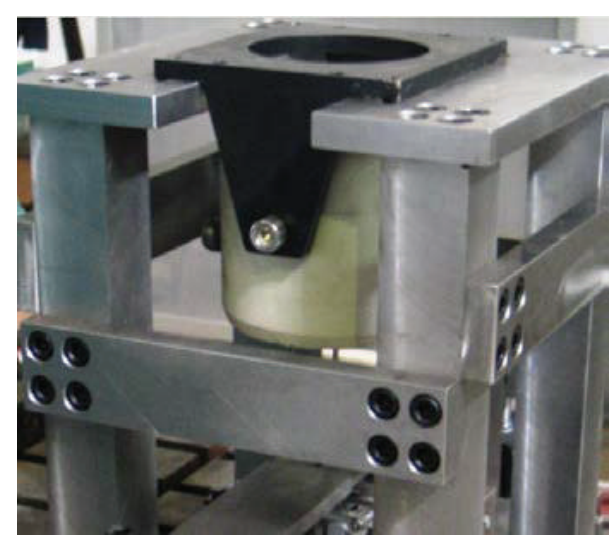

FIgURE 9: The photo of the device for applying the exciting force.

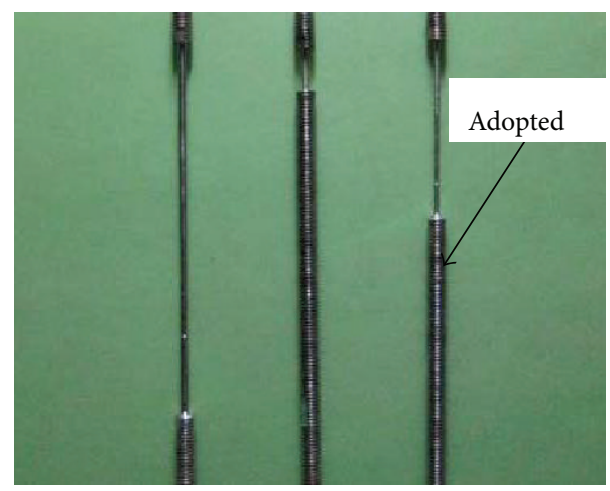

Figure 10: Three kinds of flexible rods.

and the pulley frame. The pulley is installed in the center of the U-type pulley frame. The connecting rod is connected to the magnetic base which is fixed to the platform.

3.3.4. The Device for Applying the Exciting Force. The device for applying the exciting force consists of the vibration generator, the mechanism for supporting the vibration generator, the signal generator, and the power amplifier. The sinusoidal signal is generated by the signal generator in the experiment. The sinusoidal signal is then input to the vibration generator to generate the required exciting force after amplifying by the power amplifier. In order to decrease the negative effect of additional constraints provided by the connecting structure on the measurement accuracy, the flexible rod that is shown in Figure 10 is adopted to connect the vibration generator and the beam [15]. Therefore, the beam generates sinusoidal motion under the effect of the device. After experimental comparison of the three kinds of flexible rods in Figure 10, the flexible rod in the right side which shows the best performance is applied in this experiment. Figure 9 shows the photo of the device for applying the exciting force.

3.3.5. The Measuring Device in the Experiment. The displacement of relative motion and the tangential friction force between the contact surfaces are measured in the experiment. The velocity of the relative motion is measured by the
TABle 1: Experimental conditions.

\begin{tabular}{lcccc}
\hline Number & Material & $\begin{array}{c}\text { Contact } \\
\text { radius } R / \mathrm{mm}\end{array}$ & $\begin{array}{c}\text { Normal } \\
\text { force N/N }\end{array}$ & $\begin{array}{c}\text { Exciting } \\
\text { frequency } \boldsymbol{\omega} / \mathrm{Hz}\end{array}$ \\
\hline 1 & $1 \mathrm{Cr13}$ & 6 & $\begin{array}{c}1.96,2.94, \\
\text { and } 4.90\end{array}$ & 22 \\
2 & $1 \mathrm{Cr13}$ & 18 & $\begin{array}{c}1.96,2.94, \\
\text { and } 4.90\end{array}$ & 22 \\
3 & $1 \mathrm{Cr} 13$ & 36 & $\begin{array}{c}1.96,2.94, \\
\text { and } 4.90\end{array}$ & 82 \\
\hline
\end{tabular}

OFV505/5000 laser Doppler vibrometer with the resolution of $0.3 \mu \mathrm{m} / \mathrm{s}$ made by POLYTEC Company of Germany. The displacement of the relative motion is then calculated by integration of the measured velocity. The tangential friction force is measured by the CL-YD-312 compress/stretch piezoelectric force sensor which is connected to the support device of the stationary friction specimen. The resolution and the measuring range of the sensor are $3 \mathrm{pC} / \mathrm{N}$ and $\pm 5 \mathrm{KN}$, respectively.

\section{Experimental Contents}

The dry friction contact specimens with the steam turbine blade material $1 \mathrm{Cr} 13$ are investigated by experiments in this paper. The hysteresis curves of the tangential friction force $\mathbf{f}$ versus the displacement of relative motion $\mathbf{u}$, which characterize the friction damping dynamic characteristics of the contact surfaces, are measured under different contact radii, normal forces, exciting frequencies, and displacement amplitudes of the relative motion. The radii of the friction specimen $\mathbf{R}$ include $6 \mathrm{~mm}, 18 \mathrm{~mm}$, and $36 \mathrm{~mm}$. The normal forces $\mathbf{N}$ include $1.96 \mathrm{~N}, 2.94 \mathrm{~N}$, and $4.90 \mathrm{~N}$. The exciting frequencies $\boldsymbol{\omega}$ include $22 \mathrm{~Hz}$ and $82 \mathrm{~Hz}$. In order to ensure the repeatability of the test, three pairs of the friction specimens with the same parameters are measured for each experimental condition shown in Table 1.

\section{Experimental Results Analysis}

The velocity of the relative motion $v(t)$ and the friction force $f(t)$ are measured for each experimental condition. The experimental data are analyzed in the following steps. First of all, the hysteresis curves of the friction force versus the displacement of relative motion are obtained according to the values of $v(t)$ and $f(t)$. Secondly, some key parameters such as the tangential contact stiffness, the dimensionless equivalent stiffness coefficient, and the dimensionless equivalent damping coefficient are calculated based on the hysteresis curves. Finally, the results of the parameters obtained by the experiments are compared and analyzed with that of the relevant theory models in detail.

5.1. The Hysteresis Curves of the Friction Force versus the Displacement of the Relative Motion. In order to obtain the hysteresis curve for each experimental condition, several pieces of data with the same time intervals at different time periods (usually 3-4 periods) are selected from the original 


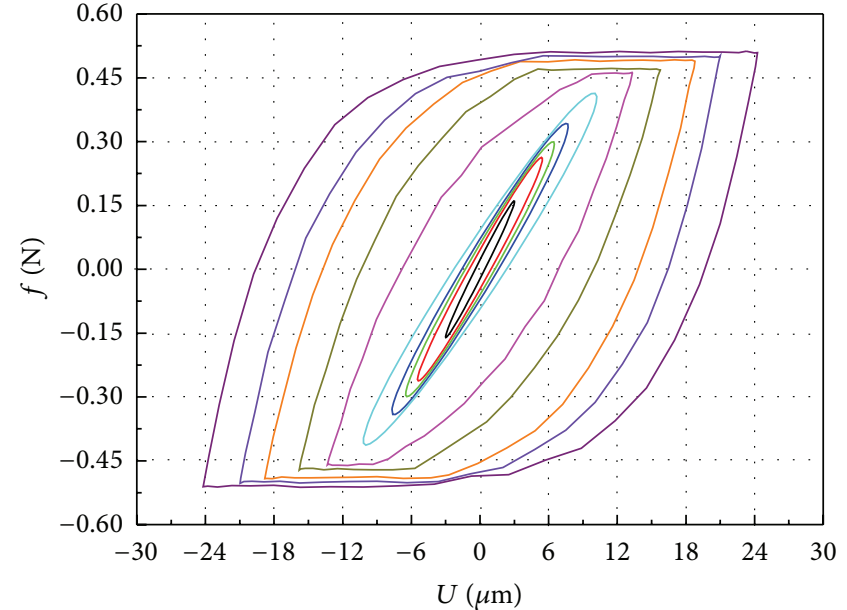

(a)

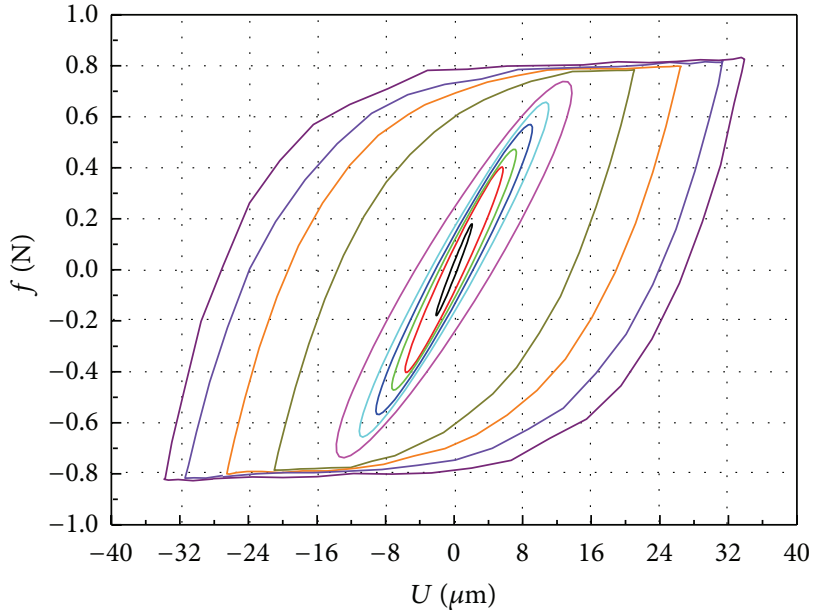

(b)

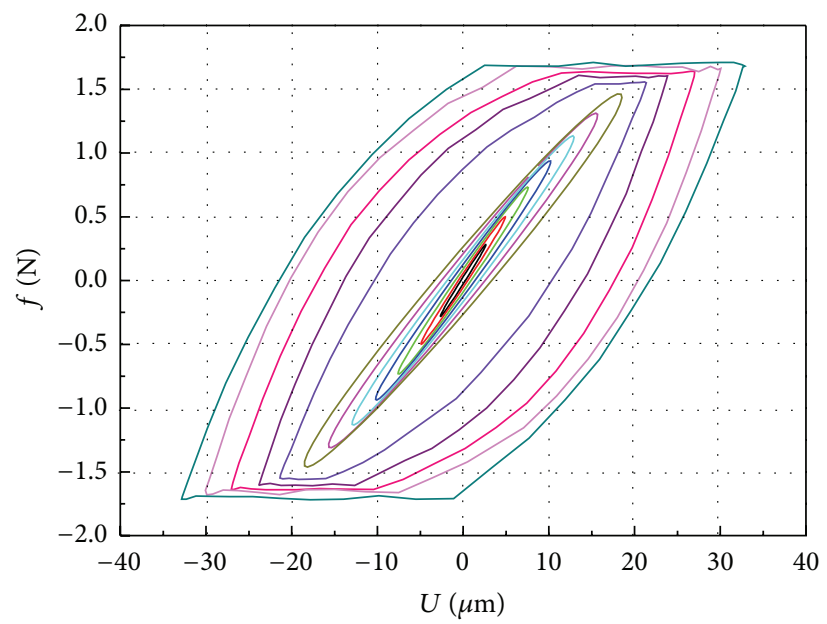

(c)

FIgure 11: The hysteresis curves when the exciting frequency is $22 \mathrm{~Hz}$. ((a) $\mathbf{N}=1.96 \mathrm{~N}$, (b) $\mathbf{N}=2.94 \mathrm{~N}$, and (c) $\mathbf{N}=4.90 \mathrm{~N}$.)

data of $v(t)$ and $f(t)$ firstly. Moreover, the hysteresis curves in a single cycle are obtained by analyzing the pieces of data at different time periods for the $v(t)$ and $f(t)$. Lastly, the hysteresis curves $f(u)$ are obtained by averaging the data of the hysteresis curves in a single cycle at different time periods:

(1) the hysteresis curves when the radius is $6 \mathrm{~mm}$ (see Figure 11),

(2) the hysteresis curves when the radius is $18 \mathrm{~mm}$ (see Figure 12),

(3) the hysteresis curves when the radius is $36 \mathrm{~mm}$ (see Figure 13).

Figures 11 to 13 show the results of the curves of the friction force versus the displacement of the relative motion for each experimental condition. The results show that the friction force of the contact surface varies as the displacement of relative motion to form a closed hysteresis curve in a single cycle. The input energy of the system increases with the increase of the amplitude of the exciting force when the exciting frequency remains unchanged. Based on the principle of conservation of energy, the dissipated energy attributed to the friction force also increases. The dissipated energy of the friction force is proportional to the area inside the hysteresis curve, which results in the increasing of the displacement amplitude of the relative motion. Therefore, the value of the displacement amplitude of relative motion depends on the amplitude of the exciting force as the exciting frequency remains unchanged. Moreover, the relative motion state of the contact surfaces turns from the condition with only microslip to the condition with both microslip and macroslip gradually as the displacement amplitude of the relative motion increases. The ratio of the macroslip period during a single cycle increases with the further increase of the displacement amplitude of the relative motion.

\subsection{The Tangential Contact Stiffness Coefficient $K_{d}$}

5.2.1. The Result of $K_{d}$ Based on the Fractal Theory. The contacts between dry friction damping structure surfaces of the steam turbine blade belong to the typical contacts 


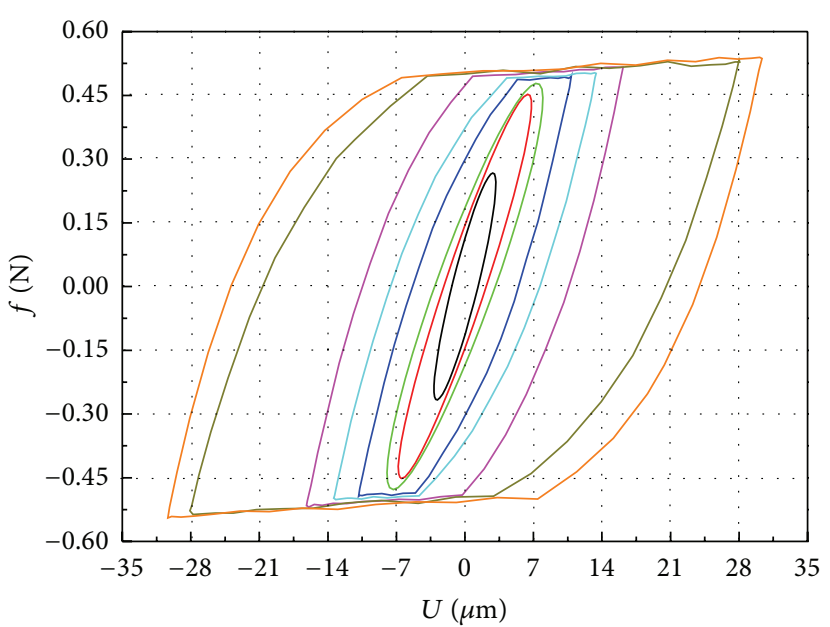

(a)

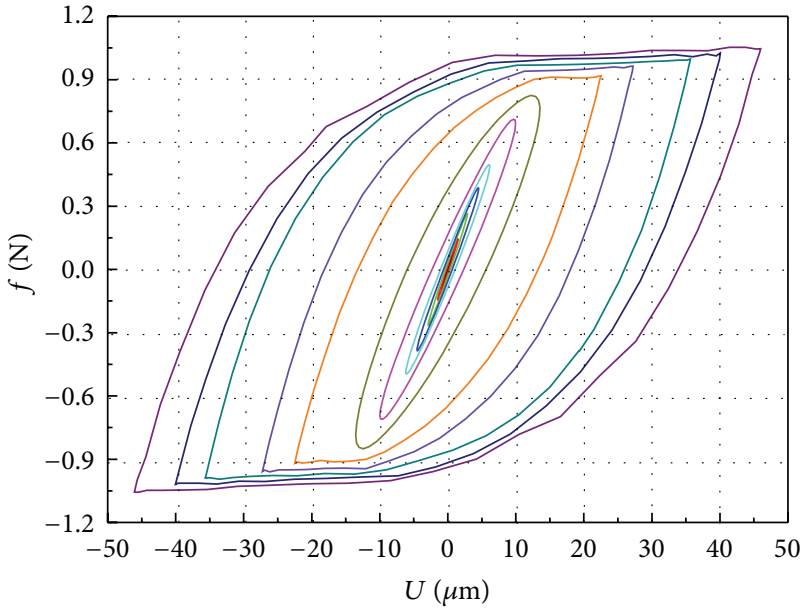

(b)

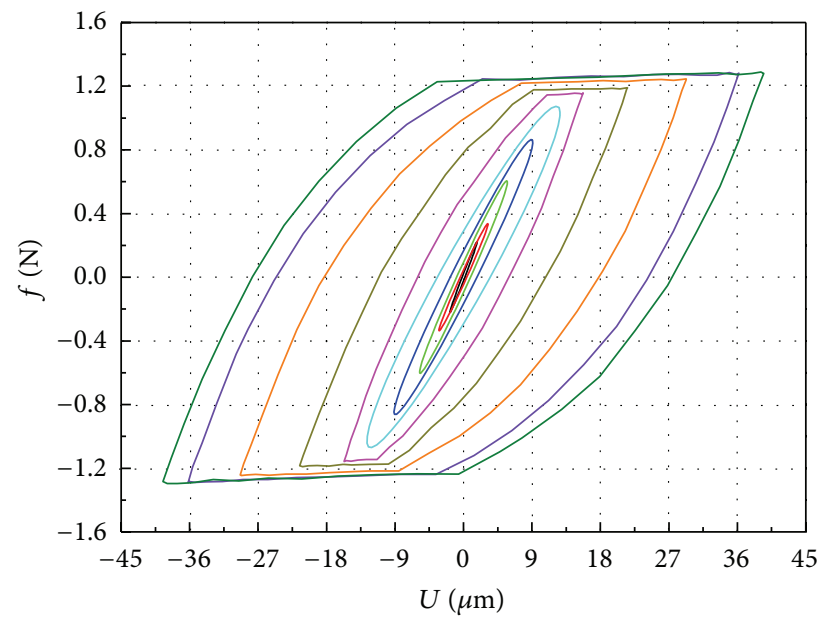

(c)

Figure 12: The hysteresis curves when the exciting frequency is $22 \mathrm{~Hz}$. ((a) $\mathbf{N}=1.96 \mathrm{~N}$, (b) $\mathbf{N}=2.94 \mathrm{~N}$, and (c) $\mathbf{N}=4.90 \mathrm{~N}$.)

of rough surfaces. The fractal geometry theory is a very important method to describe the contact characteristics of rough surfaces. Based on the fractal geometry theory and the Hertz contact theory, a theory model was proposed by Jiang et al. to investigate the contact stiffness coefficient of the machined plane joint [16]. First of all, the W-M fractal function is adopted to describe the geometry characteristics of the rough surface in this theory model. Moreover, the contact stiffness coefficient of the single spherical asperity is analyzed combined with the Hertz contact theory. Finally, the tangential contact stiffness coefficient of the whole contact surface $K_{d}$ is obtained by integration on the region of the contact area.

The $\mathrm{W}-\mathrm{M}$ fractal function can be written in a dimensionally consistent form as

$$
\begin{aligned}
z(x)= & L\left(\frac{G}{L}\right)^{D-1}(\ln \gamma)^{1 / 2} \\
& \cdot \sum_{n=0}^{n_{\max }} \gamma^{(D-2) n}\left[\cos \phi_{1 n}-\cos \left(\frac{2 \pi \gamma^{n} x}{L}-\phi_{1 n}\right)\right],
\end{aligned}
$$

where $z$-surface height; $x$-lateral distance; $D$-fractal dimension of a surface profile $(1<D<2)$; $G$-fractal roughness parameter; $\gamma$-scaling parameter for determining the spectral density and self-affine property $(\gamma=1.5) ; L-$ length of a fractal sample to be characterized; and $\phi_{1 n}-\mathrm{a}$ random phase.

The whole tangential contact stiffness $K_{d}$ can be written as

$$
K_{d}=\frac{4(1-\nu) E^{*} D}{\sqrt{2 \pi}(2-\nu)(D-1)}\left(a_{l}^{\prime(D / 2)} a_{c}^{\prime(1-D / 2)}-a_{l}^{\prime(1 / 2)}\right),
$$

where $\nu$-the Poisson ratio; $E^{*}$ - the reduced elastic modulus of the contact surfaces; $a_{l}^{\prime}$-the truncated area of the largest microcontact; and $a_{c}^{\prime}$-the critical truncated contact area.

In addition, the regularity of $K_{d}$ versus $N$ of the metallic specimen machined by milling procedure with the surface roughness of Ra3.49 was obtained in [16]. The results also indicated that $K_{d}$ is exponential with $N$. Therefore, the analysis result of $K_{d}$ versus $N$ is fitted by an exponential function according to the result of theory model. As is shown 


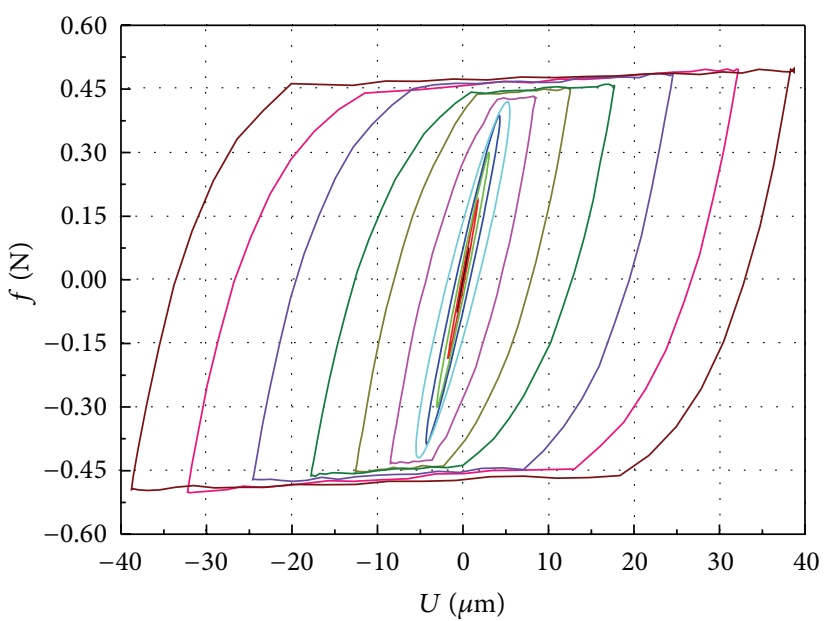

(a)

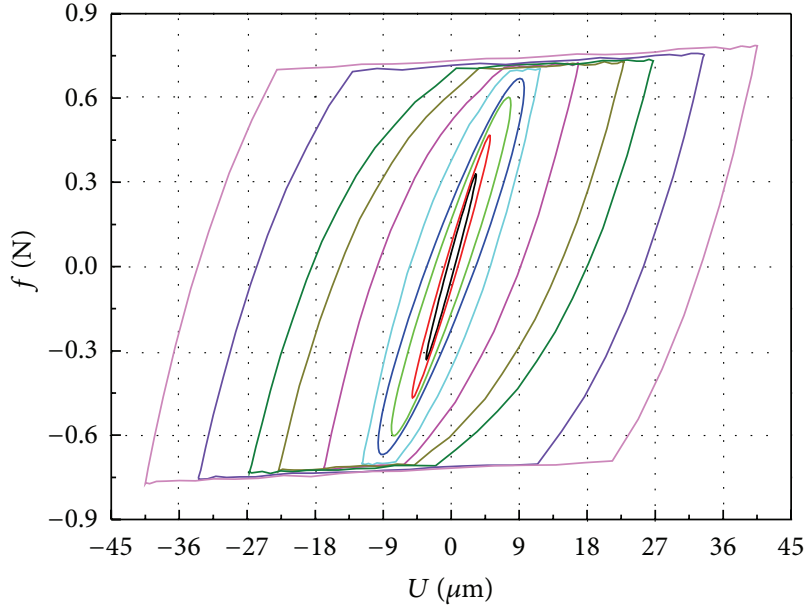

(b)

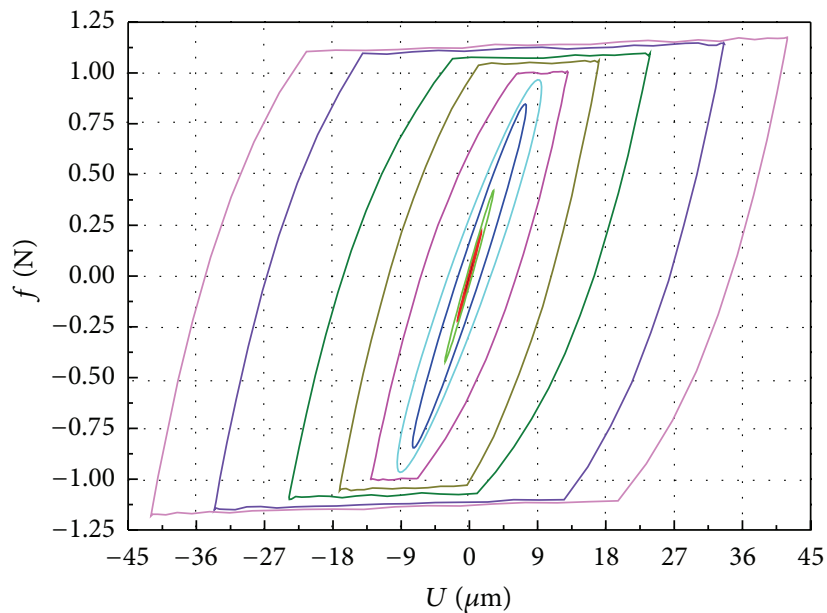

(c)

Figure 13: The hysteresis curves when the exciting frequency is $82 \mathrm{~Hz}$. ((a) $\mathbf{N}=1.96 \mathrm{~N}$, (b) $\mathbf{N}=2.94 \mathrm{~N}$, and (c) $\mathbf{N}=4.90 \mathrm{~N}$.)

in Figure 14, the fitted line of $K_{d}$ versus $N$ is obtained. The result indicates that the fitted line is in good agreement with the analysis result of the theory model.

The formula of the fitted line can be written as

$$
K_{d}=0.5924 N^{0.7616} \text {. }
$$

5.2.2. The Comparison of Experimental Results of $K_{d}$ with the Theory Results. The tangential contact stiffness of the friction contact surfaces $K_{d}$ refers to the tangential force applied to the contact surfaces when the contact surfaces generate unit tangential deformation in the state of microslip under a certain normal force. Based on the hysteresis curves obtained by the experimental analysis, the slope of the initial loading $k_{1}$ and the slop of the initial unloading $k_{2}$ during the period of microslip in the hysteresis curve are averaged to calculate the $K_{d}$.
According to the procedure which is shown in Figure 15, the formula of $K_{d}$ can be written as

$$
K_{d}=\frac{\left(k_{1}+k_{2}\right)}{2} \text {. }
$$

The metallic specimens adopted in this paper are machined by milling procedure with the surface roughness of about Ra3.2. The machined procedure and the surface roughness of the specimens in this paper are basically the same with the specimens in [16]. Therefore, the experimental results of $K_{d}$ under different conditions calculated by the method shown in Figure 15 are compared with the results of the theory model described by the fitted line. It is noted that the abscissa and ordinate in Figure 14 are denoted as the normal force and the tangential contact stiffness per unit area. The units of the abscissa and ordinate are $\mathrm{MPa}$ and $\mathrm{MPa} / \mathrm{m}$, respectively. However, the abscissa and ordinate in Figure 16 are denoted as the normal force and the tangential contact stiffness without having an average in the area. The units of the abscissa and ordinate are $\mathrm{N}$ and $\mathrm{N} / \mathrm{m}$, respectively. As a result, the 


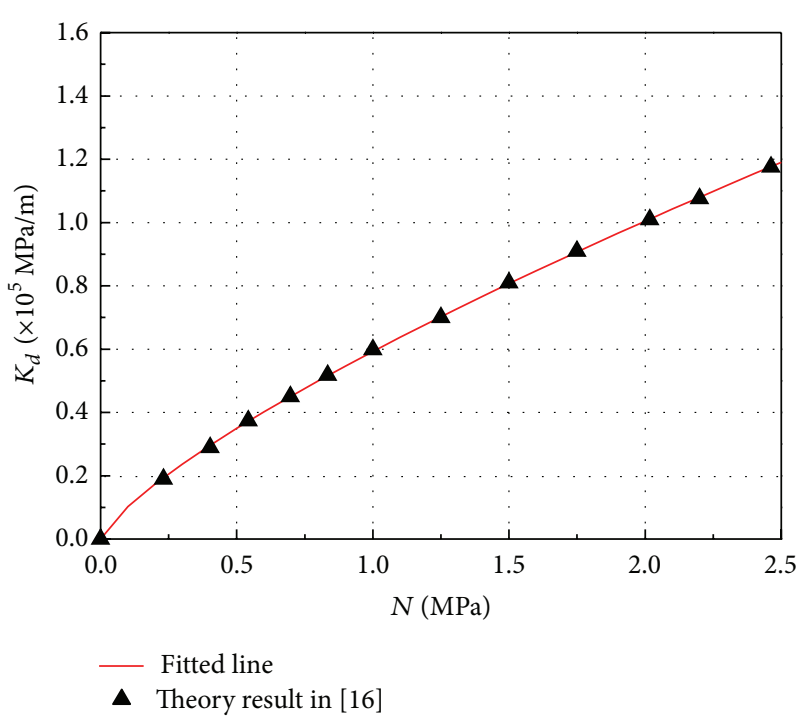

FIgURE 14: The result of $K_{d}$ versus $N$.

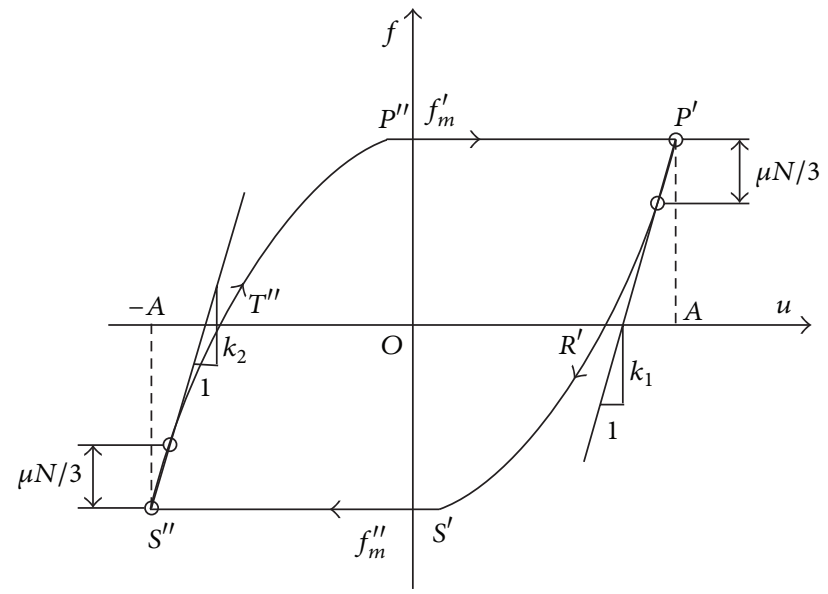

FIGURE 15: The calculation procedure of $K_{d}$ based on the hysteresis curve by the experiments [12].

units of the results between Figures 14 and 16 are equivalent. Figure 16 shows the comparison of the experimental results of $K_{d}$ with that of the theory results under each condition. It is indicated that the experimental results are in good agreement with the theory results. Therefore, the theory model based on the fractal theory and the Hertz contact theory in [16] can be adopted to predict the $K_{d}$ between the dry friction contact surfaces of the steam turbine blade material with sufficient accuracy.

5.3. The Coefficients of the Dimensionless Equivalent Stiffness and Equivalent Damping. According to the hysteresis curves of the friction force versus the displacement of relative motion $f(u)$ described by formula (1) and formula (2), the first order harmonic components of the friction force $f_{c}$ and $f_{s}$ are calculated by the harmonic balance method (HBM) firstly. Moreover, the dimensionless components of the friction force are obtained by the assumption of

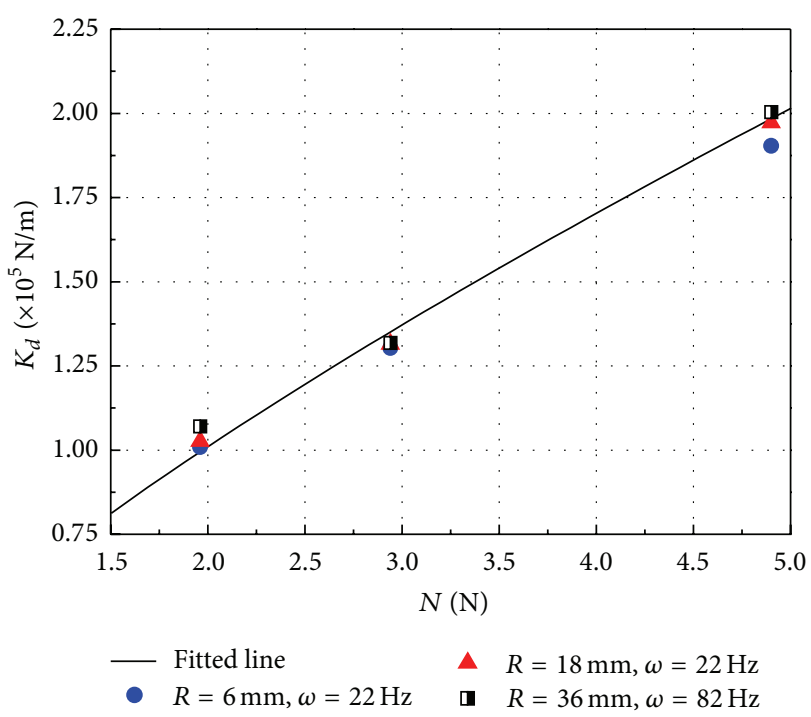

FIGURE 16: The comparison of the experimental result of $K_{d}$ with that of the theory model.

$\widetilde{A}=A / A_{0}, \widetilde{u}=u / A_{0}, \tilde{f}=f / \mu N$, and $\tilde{f}^{*}=f^{*} / \mu N$. Finally, the coefficients of dimensionless equivalent stiffness $\widetilde{K}_{\mathrm{eq}}$ and equivalent damping $\widetilde{C}_{\mathrm{eq}}$ are calculated by the numerical integration method. The schematic diagram of the analysis process is shown in Figure 17.

5.3.1. $\widetilde{K}_{e q}$ and $\widetilde{C}_{e q}$ of the Theory Models. The curves of $\widetilde{K}_{\mathrm{eq}}$ versus the dimensionless displacement amplitude of the relative motion $\widetilde{A}$ and $\widetilde{C}_{\mathrm{eq}}$ versus $\widetilde{A}$ of the macroslip hysteresis model and the Mindlin microslip model are calculated by the analysis method shown in Figure 17. The results in Figures 18 and 19 show that $\widetilde{K}_{\text {eq }}$ decreases with the increase of $\widetilde{A}$. Unlike the regularity of $\widetilde{K}_{\text {eq }}, \widetilde{C}_{\text {eq }}$ first increases and then decreases as the $\widetilde{A}$ increases which results in a maximum value of $\widetilde{C}_{\text {eq }}$.

5.3.2. The Comparison of Experimental Curves of $\widetilde{K}_{e q}$ and $\widetilde{C}_{e q}$ with the Theory Curves. Based on the results of hysteresis curves from the experimental analysis, the $\widetilde{K}_{\mathrm{eq}}$ and $\widetilde{C}_{\mathrm{eq}}$ for each condition shown in Table 1 are obtained by the method shown in Figure 17. The changing regularities of $\widetilde{K}_{\mathrm{eq}}$ and $\widetilde{C}_{\mathrm{eq}}$ under different parameters are analyzed in detail. In addition, the experimental results of $\widetilde{K}_{\mathrm{eq}}$ and $\widetilde{C}_{\mathrm{eq}}$ are compared with that of the theory models in detail.

(1) The Effects of the Experimental Parameters on $\widetilde{K}_{e q}$ and $\widetilde{C}_{e q}$. Figures 20 to 22 show the analysis results of the friction specimens with the material of $1 \mathrm{Cr} 13$ under different parameters, including the displacement amplitude of the relative motion $\mathbf{A}$, the normal force $\mathbf{N}$, the contact radius $\mathbf{R}$, and the exciting frequency $\boldsymbol{\omega}$. In order to investigate the friction damping characteristics of the contact surfaces deeply, the effects of the above parameters on $\widetilde{K}_{\mathrm{eq}}$ and $\widetilde{C}_{\mathrm{eq}}$ are discussed in detail below. 


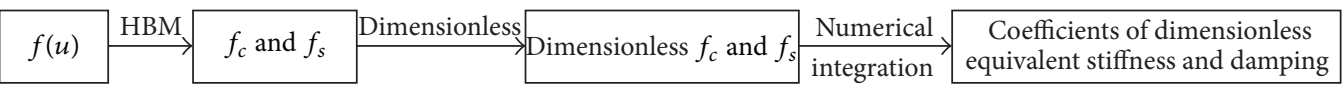

FIGURE 17: The analysis process of the dimensionless equivalent stiffness and damping coefficients.

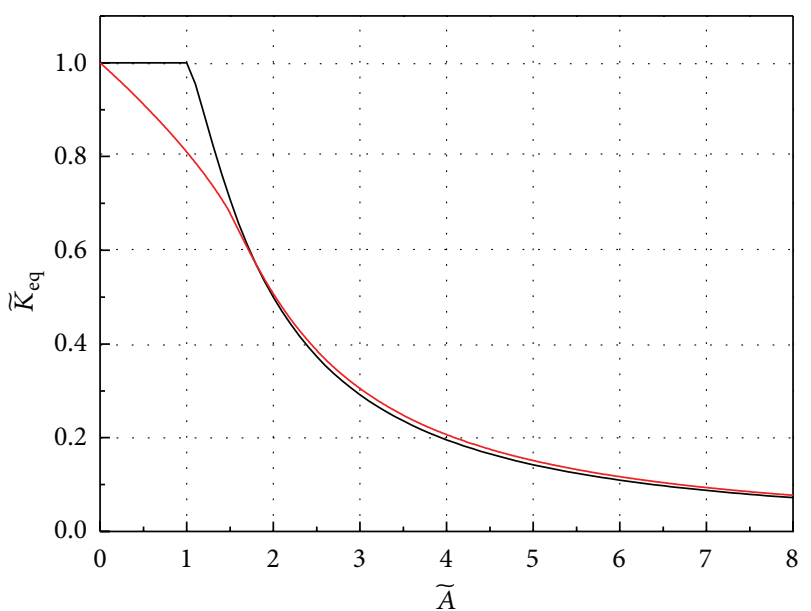

_ Macroslip hysteresis model

— Mindlin microslip model

FIgURE 18: The theory curves of $\widetilde{K}_{\text {eq }}$ versus $\widetilde{A}$.

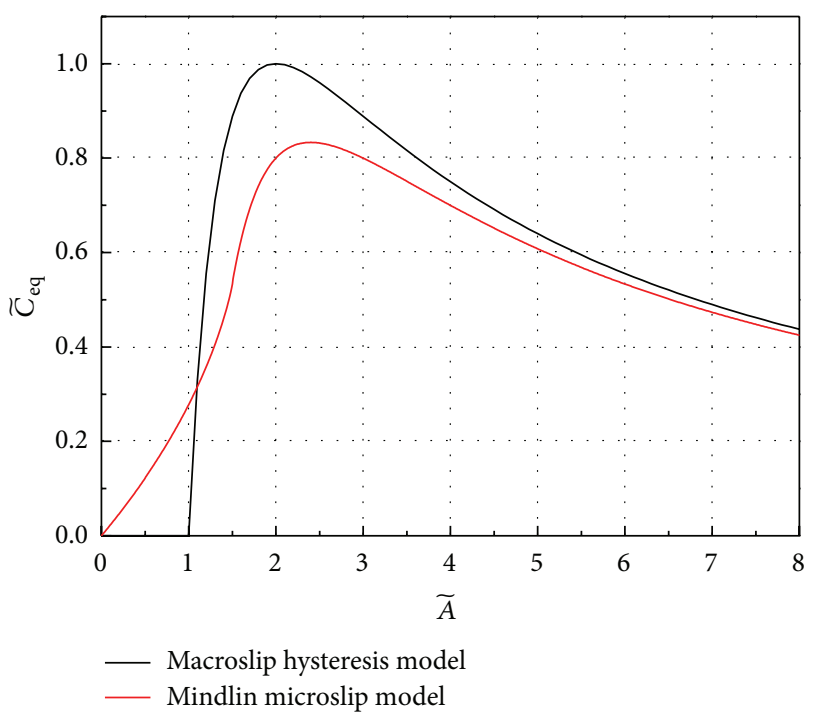

FIgURE 19: The theory curves of $\widetilde{C}_{\mathrm{eq}}$ versus $\widetilde{A}$.

Based on the dimensionless assumption of the parameters, the displacement amplitude of the relative motion $\mathbf{A}$ is proportional to the dimensionless displacement amplitude of the relative motion $\widetilde{A}$ when other parameters keep constant. In this condition, $\mathbf{A}$ can be replaced by $\widetilde{A}$ to investigate the effects of $\mathbf{A}$ on $\widetilde{K}_{\text {eq }}$ and $\widetilde{C}_{\text {eq }}$. The above experimental results indicate that $\widetilde{K}_{\text {eq }}$ gradually decreases with the increase of $\widetilde{A}$ on the one hand. On the other hand, $\widetilde{C}_{\mathrm{eq}}$ first increases and then decreases as $\widetilde{A}$ increases. Moreover, $\widetilde{C}_{\mathrm{eq}}$ decreases slowly after reaching the maximum value as $\widetilde{A}$ increases. On the one side, the value of the slip area between the contact surfaces increases from zero to a large number and even the value of the contact surface as $\widetilde{A}$ increases gradually. It becomes easier and easier to generate relative slip motion between the contact surfaces, which results in the decrease of $\widetilde{K}_{\text {eq }}$. On the other side, $\widetilde{C}_{\text {eq }}$ increases significantly when the friction energy dissipation between the contact surfaces increases in the beginning. However, the amplitude of the friction force does not increase anymore when the relative motion between the contact surfaces reaches the state of pure macroslip. In this condition, the increasing rate of the friction energy dissipation decreases significantly to less than the increasing rate of the input energy of the system. As a result, $\widetilde{C}_{\mathrm{eq}}$ increases slowly and begins to decrease slowly after reaching its maximum value. The experimental results in Figures 20 to 22 also show that $\widetilde{K}_{\text {eq }}$ and $\widetilde{C}_{\text {eq }}$ remain almost unchanged when other parameters, including the normal force $\mathbf{N}$, the contact radius $\mathbf{R}$, and the exciting frequency $\boldsymbol{\omega}$, vary. Therefore, it can be concluded that $\widetilde{K}_{\text {eq }}$ and $\widetilde{C}_{\text {eq }}$ between the contact surfaces are independent with $\mathbf{N}, \mathbf{R}$, and $\boldsymbol{\omega}$. The amplitude of the friction force increases with the increase of $\mathbf{N}$ when other parameters remain unchanged, which results in the increase of the equivalent stiffness coefficient $\mathbf{K}_{\mathrm{eq}}$ and the equivalent damping coefficient $\mathbf{C}_{\text {eq }}$. However, the tangential contact stiffness coefficient $\mathbf{K}_{d}$ increases with the increase of $\mathrm{N}$. The above two effects cancel each other out. As a result, $\widetilde{K}_{\text {eq }}$ and $\widetilde{C}_{\text {eq }}$ remain unchanged for $\widetilde{K}_{\text {eq }}=\mathbf{K}_{\text {eq }} / \mathbf{K}_{d}$ and $\widetilde{C}_{\mathrm{eq}}=$ $\mathrm{C}_{\mathrm{eq}} /\left(\mathbf{K}_{d} / \pi \boldsymbol{\omega}\right)$. The value of the contact area increases with the increase of $\mathbf{R}$, and which is also results in the decrease of the contact pressure when $\mathbf{N}$ remains unchanged. The tangential contact stiffness coefficient $\mathbf{K}_{d}$ remains unchanged for the effects of $\mathbf{R}$ and the contact pressure cancel each other out. Therefore, $\widetilde{K}_{\text {eq }}$ and $\widetilde{C}_{\text {eq }}$ are independent with $\mathbf{R}$. Although $\mathbf{C}_{\text {eq }}$ is dependent with $\omega, \widetilde{K}_{\text {eq }}$, and $\widetilde{C}_{\text {eq }}$ being independent with $\omega$ according to their final expressions. As a result, $\widetilde{K}_{\text {eq }}$ and $\widetilde{C}_{\text {eq }}$ remain unchanged as $\omega$ varies.

(2) The Comparison of Experimental Results with the Results of Theory Models. The experimental analysis results are compared with the results of the two theory models in this paper. According to the comparison results of Figures 2022 , the variation trends and values of $\widetilde{K}_{\text {eq }}$ and $\widetilde{C}_{\mathrm{eq}}$ of the macroslip hysteresis model agree well with the experimental results under each condition when $\widetilde{A}$ is relatively large $(\widetilde{A}$ is greater than 1 1.5). However, the results of the macroslip hysteresis model differ a lot from the experimental results both in variation trends and values when $\widetilde{A}$ is relatively small ( $\widetilde{A}$ is smaller than 1 1.5). The contact surface is in the state of pure microslip or microslip with most regions when $\widetilde{A}$ is relatively small. The microslip effect between the contact 


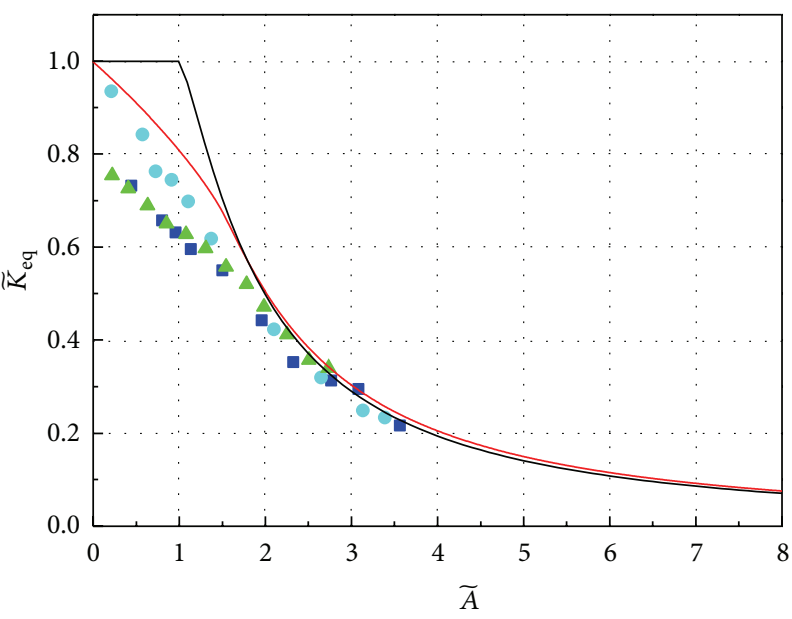

Theory-macroslip hysteresis model

- Theory-Mindlin model

- Experiment $-\mathrm{N}=1.96 \mathrm{~N}$

- Experiment $-N=2.94 \mathrm{~N}$

$\triangle$ Experiment $-N=4.90 \mathrm{~N}$

(a) The curves of $\widetilde{K}_{\text {eq }}$ versus $\widetilde{A}$

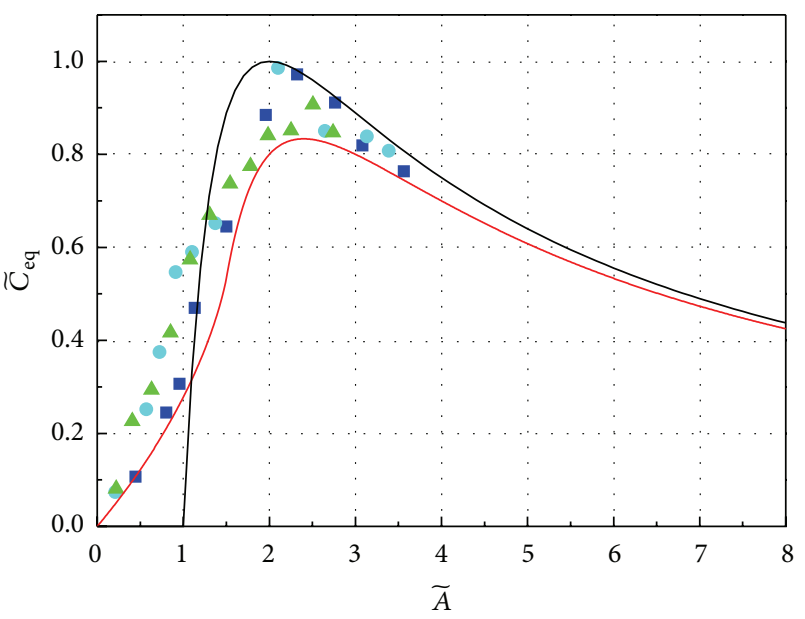

- Theory-macroslip hysteresis model

— Theory-Mindlin model

- Experiment $-N=1.96 \mathrm{~N}$

- Experiment $-\mathrm{N}=2.94 \mathrm{~N}$

$\triangle$ Experiment $-\mathrm{N}=4.90 \mathrm{~N}$

(b) The curves of $\widetilde{C}_{\text {eq }}$ versus $\widetilde{A}$

FIGURE 20: The comparison of the results when the exciting frequency is $22 \mathrm{~Hz}$ and the contact radius is $6 \mathrm{~mm}$.

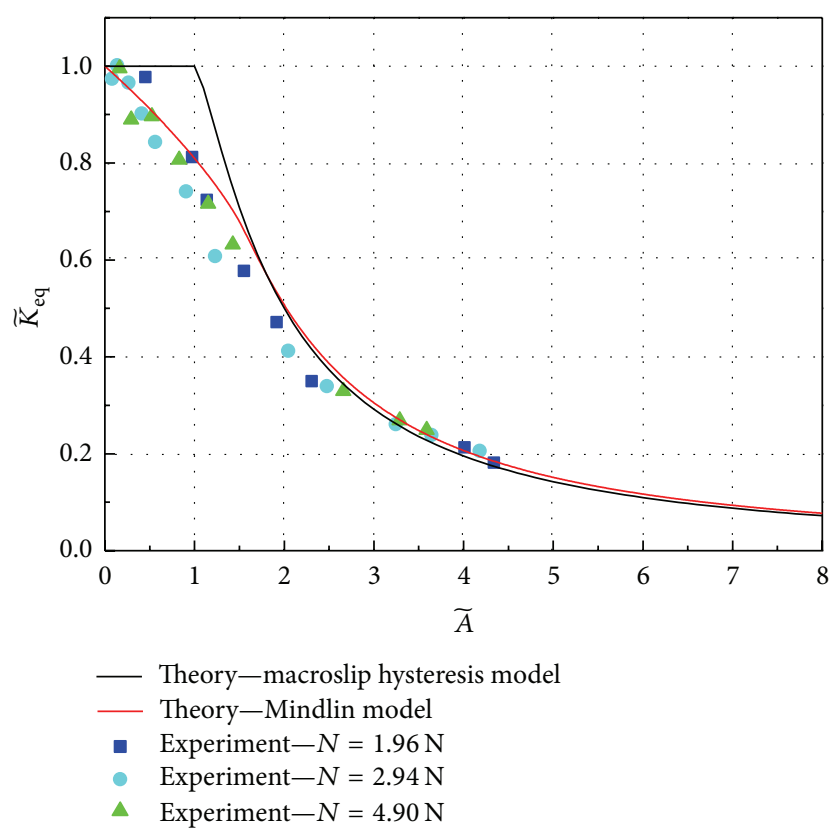

(a) The curves of $\widetilde{K}_{\text {eq }}$ versus $\widetilde{A}$

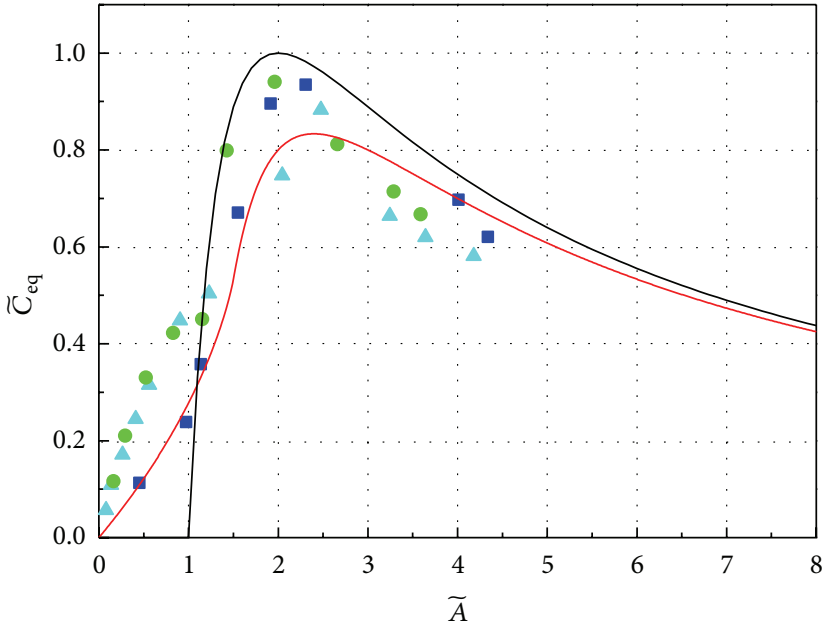

— Theory-macroslip hysteresis model

- Theory-Mindlin model

- Experiment $-N=1.96 \mathrm{~N}$

- Experiment $-\mathrm{N}=2.94 \mathrm{~N}$

$\triangle$ Experiment $-\mathrm{N}=4.90 \mathrm{~N}$

(b) The curves of $\widetilde{C}_{\mathrm{eq}}$ versus $\widetilde{A}$

FIGURE 21: The comparison of the results when the exciting frequency is $22 \mathrm{~Hz}$ and the contact radius is $18 \mathrm{~mm}$.

surfaces is neglected in the macroslip hysteresis model, which results in the great difference between the results of this model with the experimental results. The microslip effect can be ignored for the state of pure macroslip plays a dominate role in the relative motion of the contact surfaces when $\widetilde{A}$ is relatively large. Therefore, the results of this model agree well with the experimental results in this condition. The microslip effect is adequately considered in Mindlin microslip friction model, which results in the good predictions of the results of $\widetilde{K}_{\text {eq }}$ and $\widetilde{C}_{\text {eq }}$ during the whole experimental measurement range.

(3) The Linearization of $\widetilde{K}_{e q}$ and $\widetilde{C}_{e q}$. According to the above analysis results, $\widetilde{K}_{\text {eq }}$ and $\widetilde{C}_{\text {eq }}$ calculated by the Mindlin 


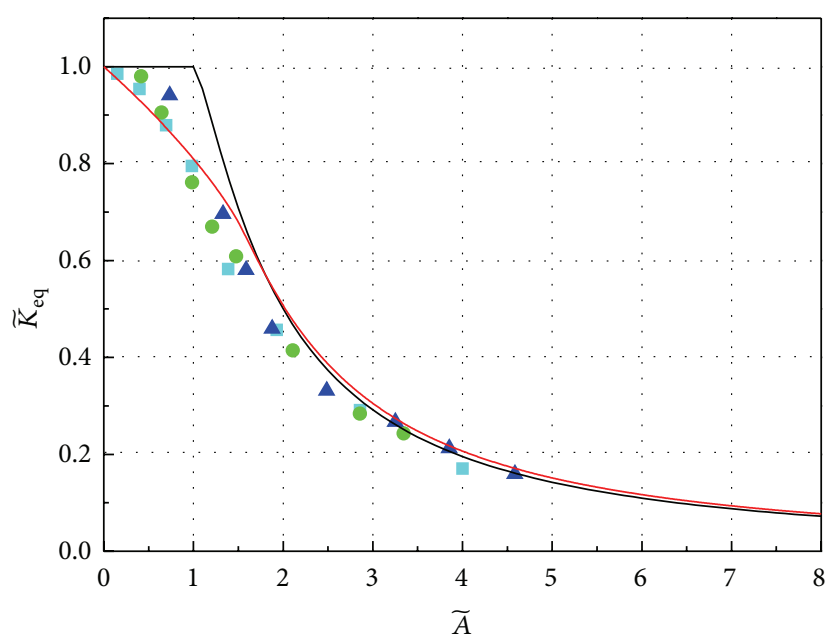

Theory-macroslip hysteresis model
Theory-Mindlin model
Experiment $-N=1.96 \mathrm{~N}$
Experiment $-N=2.94 \mathrm{~N}$
Experiment $-N=4.90 \mathrm{~N}$

(a) The curves of $\widetilde{K}_{\text {eq }}$ versus $\widetilde{A}$

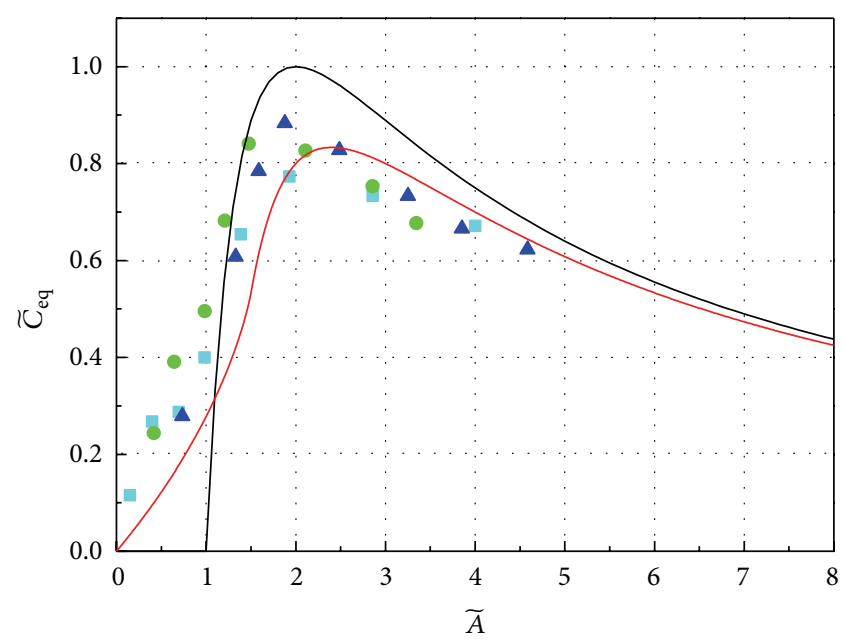

Theory-macroslip hysteresis model
Theory-Mindlin model
Experiment $-N=1.96 \mathrm{~N}$
Experiment $-N=2.94 \mathrm{~N}$
Experiment $-N=4.90 \mathrm{~N}$

(b) The curves of $\widetilde{C}_{\text {eq }}$ versus $\widetilde{A}$

FIGURE 22: The comparison of the results when the exciting frequency is $82 \mathrm{~Hz}$ and the contact radius is $36 \mathrm{~mm}$.

microslip friction model agree well with the experimental results. Therefore, the Mindlin microslip friction model can be used to predict $\widetilde{K}_{\text {eq }}$ and $\widetilde{C}_{\text {eq }}$ during the vibration analysis of the steam turbine blade with dry friction damping structures. The results also show that both the relationships between $\widetilde{K}_{\text {eq }}$ and $\widetilde{A}$ and between $\widetilde{C}_{\text {eq }}$ and $\widetilde{A}$ are characterized by strong nonlinearity, which adds to the difficulty of building the vibration analysis model of the steam turbine blade with dry friction damping structures in actual engineering applications. The results show that $\widetilde{K}_{\text {eq }}$ decreases with the increase of $\widetilde{A}$. $\widetilde{C}_{\mathrm{eq}}$ first increases and then decreases with the increase of $\widetilde{A}$ and reaches the maximum value when $\widetilde{A} \approx 2$. Based on the experimental results during the measurement range, $\widetilde{K}_{\text {eq }}$ and $\widetilde{C}_{\text {eq }}$ are linearized by the least square method both in the range of $0 \leq \widetilde{A}<2$ and $2 \leq \widetilde{A} \leq 4.5$, respectively. The linearity regularities of $\widetilde{K}_{\mathrm{eq}}$ versus $\widetilde{A}$ and $\widetilde{C}_{\mathrm{eq}}$ versus $\widetilde{A}$ are obtained, which decrease the difficulty of building the vibration analysis model of the blade with sufficient accuracy. The results of the linearization are shown in Figures 23 and 24.

The linearization formulae of $\widetilde{K}_{\text {eq }}$ and $\widetilde{C}_{\text {eq }}$ are

$$
\begin{aligned}
& \widetilde{K}_{e}= \begin{cases}-0.2794 \widetilde{A}+1 & 0 \leq \widetilde{A}<2 \\
-0.1293 \widetilde{A}+0.6998 & 2 \leq \widetilde{A} \leq 4.5\end{cases} \\
& \widetilde{C}_{e}= \begin{cases}0.4610 \widetilde{A} & 0 \leq \widetilde{A}<2 \\
-0.1335 \widetilde{A}+1.1890 & 2 \leq \widetilde{A} \leq 4.5 .\end{cases}
\end{aligned}
$$

\section{Conclusions}

In this paper, a rig for the test of dry friction damping dynamic characteristics of the steam turbine blade material
$1 \mathrm{Cr} 13$ is built. The friction damping dynamic characteristics of the specimens with nonconforming contact surfaces are investigated in detail under different parameters, including the displacement amplitude of the relative motion $\mathbf{A}$, the normal force $\mathbf{N}$, the contact radius $\mathbf{R}$, and the exciting frequency $\boldsymbol{\omega}$. The main conclusions are as follows.

(1) The friction force of the contact surface varies as the displacement of relative motion to form a closed hysteresis curve in a single cycle. The relative motion state of the contact surfaces turns from the condition with only microslip to the condition with both microslip and macroslip gradually as the displacement amplitude of the relative motion increases. In addition, the ratio of the macroslip period during a single cycle increases with the further increase of the displacement amplitude of the relative motion.

(2) The experimental result of the tangential contact stiffness $K_{d}$ is in good agreement with that of the theory results. The theory model based on the fractal theory and the Hertz contact theory in [16] can be adopted to predict the $K_{d}$ between the dry friction contact surfaces of the steam turbine blade material with sufficient accuracy.

(3) The influence regularities of different parameters on the coefficients of dimensionless equivalent stiffness $\widetilde{K}_{\text {eq }}$ and equivalent damping $\widetilde{C}_{\text {eq }}$ are obtained. $\widetilde{K}_{\text {eq }}$ gradually decreases with the increase of $\widetilde{A}$ as other parameters remain unchanged. In this condition, $\widetilde{C}_{\mathrm{eq}}$ first increases and then decreases as $\widetilde{A}$ increases. Moreover, $\widetilde{C}_{\text {eq }}$ decreases slowly after reaching the maximum value as $\widetilde{A}$ increases. It can also be concluded that $\widetilde{K}_{\text {eq }}$ and $\widetilde{C}_{\text {eq }}$ between the contact surfaces are independent with $\mathbf{N}, \mathbf{R}$, and $\boldsymbol{\omega}$. 


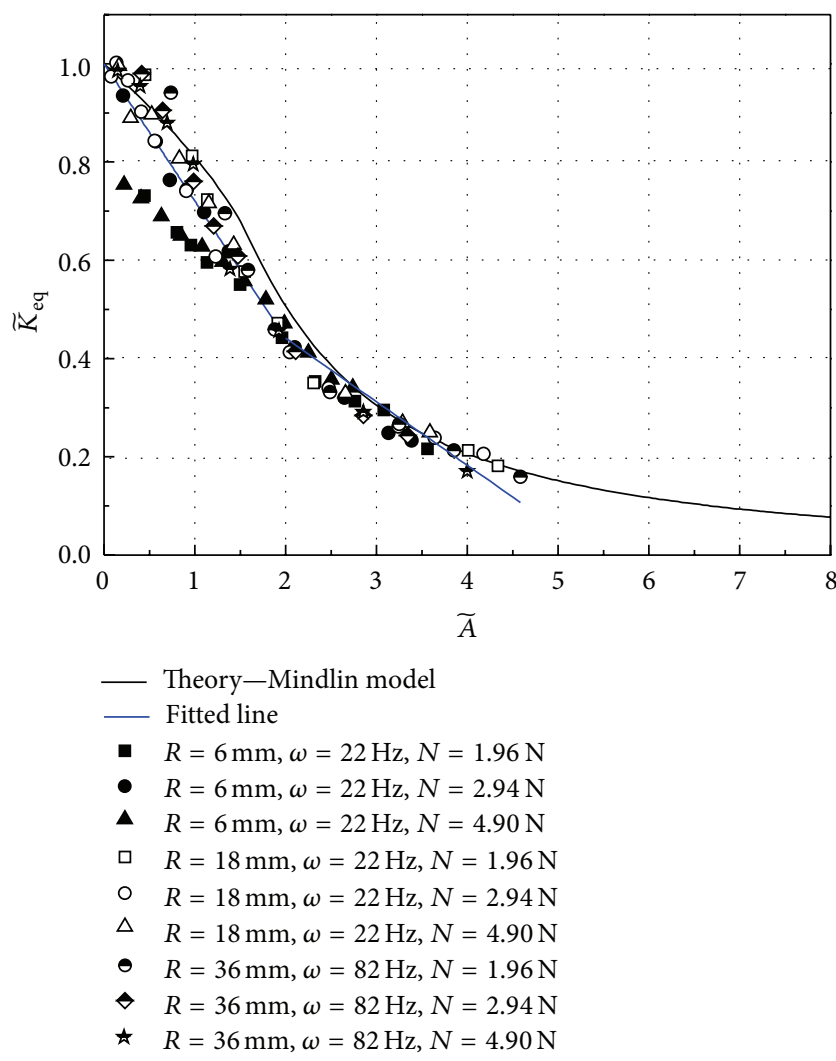

FIGURE 23: The linearization results of $\widetilde{K}_{\text {eq }}$.

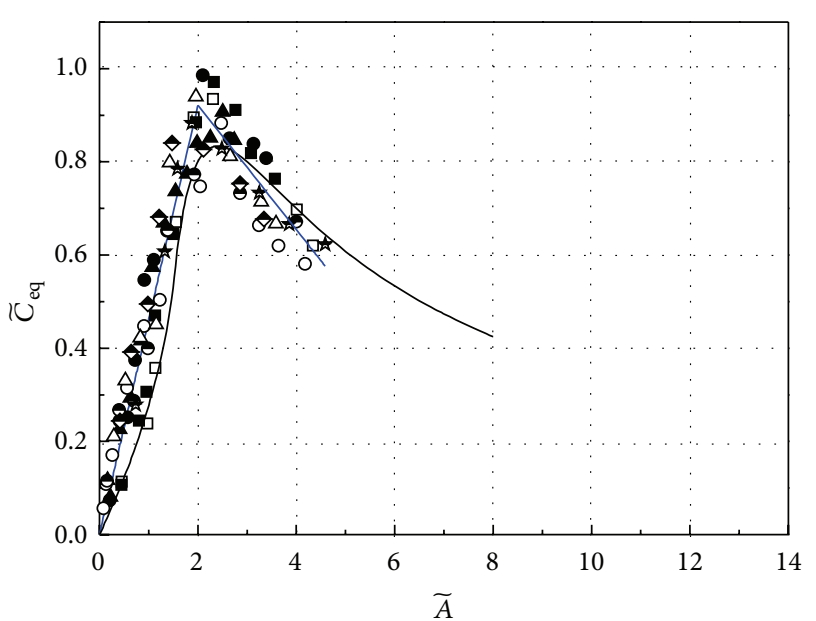

\footnotetext{
— Theory-Mindlin model

- Fitted line

- $R=6 \mathrm{~mm}, \omega=22 \mathrm{~Hz}, N=1.96 \mathrm{~N}$

- $R=6 \mathrm{~mm}, \omega=22 \mathrm{~Hz}, N=2.94 \mathrm{~N}$

- $R=6 \mathrm{~mm}, \omega=22 \mathrm{~Hz}, N=4.90 \mathrm{~N}$

ㅁ $R=18 \mathrm{~mm}, \omega=22 \mathrm{~Hz}, N=1.96 \mathrm{~N}$

○ $R=18 \mathrm{~mm}, \omega=22 \mathrm{~Hz}, N=2.94 \mathrm{~N}$

$\triangle R=18 \mathrm{~mm}, \omega=22 \mathrm{~Hz}, N=4.90 \mathrm{~N}$

- $R=36 \mathrm{~mm}, \omega=82 \mathrm{~Hz}, N=1.96 \mathrm{~N}$

$\diamond R=36 \mathrm{~mm}, \omega=82 \mathrm{~Hz}, N=2.94 \mathrm{~N}$

$\star R=36 \mathrm{~mm}, \omega=82 \mathrm{~Hz}, N=4.90 \mathrm{~N}$
}

FIGURE 24: The linearization results of $\widetilde{C}_{\mathrm{eq}}$.
(4) The results of $\widetilde{K}_{\mathrm{eq}}$ and $\widetilde{C}_{\mathrm{eq}}$ of the macroslip hysteresis model agree well with the experimental results under each condition when $\widetilde{A}$ is relatively large. However, the results of this theory model differ a lot from the experimental results when $\widetilde{A}$ is relatively small. The microslip effect is adequately considered in Mindlin microslip friction model, which results in the good predictions of the results of $\widetilde{K}_{\mathrm{eq}}$ and $\widetilde{C}_{\mathrm{eq}}$ during the whole measurement range.

(5) In order to decrease the difficulty of building the vibration analysis model of the steam turbine blade with dry friction damping structures in actual engineering applications, $\widetilde{K}_{\text {eq }}$ and $\widetilde{C}_{\text {eq }}$ are linearized by the least square method both in the range of $0 \leq \widetilde{A}<2$ and $2 \leq \widetilde{A} \leq 4.5$, respectively. The linearity regularities of $\widetilde{K}_{\mathrm{eq}}$ versus $\widetilde{A}$ and $\widetilde{C}_{\mathrm{eq}}$ versus $\widetilde{A}$ are obtained, which decrease the difficulty of building the vibration analysis model of the blade with sufficient accuracy.

\section{Conflict of Interests}

The authors declare that there is no conflict of interests regarding the publication of this paper.

\section{Acknowledgments}

The authors are grateful for the financial support from the National High Technology Research and Development of China (863 Program) (2009AA04Z102). Special thanks should go to some graduate students such as Qiang Zhang, Minghui Zhang, Junjie Deng, and Pengfei Zhao who have put considerable time and effort into their comments on the draft.

\section{References}

[1] Z. Zihui and X. Yonghui, "A review of research on damper of turbine blade," Turbine Technology, vol. 50, no. 1, pp. 1-5, 2008 (Chinese).

[2] G. Csaba, Modelling Microslip Friction Damping and Its Influence on Turbine Blade Vibrations, University of Linköping, Linköping, Sweden, 1998.

[3] L.-L. Chen, Y.-H. Ma, D. Li, and J. Hong, "Measurement of contact stiffness during microslip," Journal of Aerospace Power, vol. 25, no. 4, pp. 936-942, 2010 (Chinese).

[4] R. D. Mindlin, W. P. Mason, I. F. Osmer et al., "Effects of an oscillating tangential force on the contact surfaces of elastic spheres," in Proceedings of the 1st U.S. National Congress of Applied Mechanics, pp. 203-208, 1951.

[5] L. E. Goodman and C. B. Brown, "Energy dissipation in contact friction: constant normal and cyclic tangential loading," ASME Journal of Applied Mechanics, vol. 29, no. 1, pp. 17-22, 1962.

[6] J. W. Liang and B. F. Feeny, "Identification of coulomb and viscous friction from free-vibration decrements," Nonlinear Dynamics, vol. 16, no. 4, pp. 337-347, 1998.

[7] J.-W. Liang and B. F. Feeny, "Identifying Coulomb and viscous friction in forced dual-damped oscillators," Journal of Vibration and Acoustics, Transactions of the ASME, vol. 126, no. 1, pp. 118125, 2004. 
[8] S. Filippi, A. Akay, and M. M. Gola, "Measurement of tangential contact hysteresis during microslip," Journal of Tribology, vol. 126, no. 3, pp. 482-489, 2004.

[9] Q. Lin, Z.-Y. Hao, and Y.-H. Liu, “Test and simulation for dry friction characteristics of metallic materials," Journal of Zhejiang University (Engineering Science), vol. 43, no. 8, pp. 1501-1505, 2009 (Chinese).

[10] Y.-C. Shan, Y.-P. Hao, Z.-G. Zhu, and L.-T. Yan, "Application and development of platform friction damper for depressing resonant vibration of blades," Journal of Aerospace Power, vol. 16, no. 3, pp. 218-223, 2001 (Chinese).

[11] H. Bai and X. Huang, "An overview on study of methods of response computation for the dry frictinally damped vibration systems," Advances in Mechanics, vol. 31, no. 4, pp. 524-534, 2001 (Chinese).

[12] K. H. Koh, J. H. Griffin, S. Filippi, and A. Akay, "Characterization of turbine blade friction dampers," Journal of Engineering for Gas Turbines and Power, vol. 127, no. 4, pp. 856-862, 2005.

[13] J. H. Zhai, Numerical Anlaysis on Contact Problems of Layered Solid, Jiangsu University, Zhenjiang, China, 2006, (Chinese).

[14] L. Panning, K. Popp, W. Sextro, F. Götting, A. Kayser, and I. Wolter, "Asymmetrical underplatform dampers in gas turbine bladings: theory and application," in Proceedings of the ASME Turbo Expo 2004, GT2004-53316, pp. 269-280, ASME, Vienna, Austria, 2004.

[15] Z. Jian, S. Zhanglin, Z. Junhua et al., "How to ensure the accuracy of measurement of dynamic characteristics of structures," Journal of Chendu University of Science and Technology, vol. 16, no. 2, pp. 133-136, 1984 (Chinese).

[16] S. Y. Jiang, Y. J. Zheng, and H. Zhu, "A contact stiffness model of machined plane joint based on fractal theory," Journal of Tribology, vol. 132, no. 1, Article ID 011401, 7 pages, 2009.

[17] Y. Shan, Investigation on the Vibration Control of Turbo-Machine Blade by Dry Friction Damping, Beihang University, Beijing, China, 2002, (Chinese). 

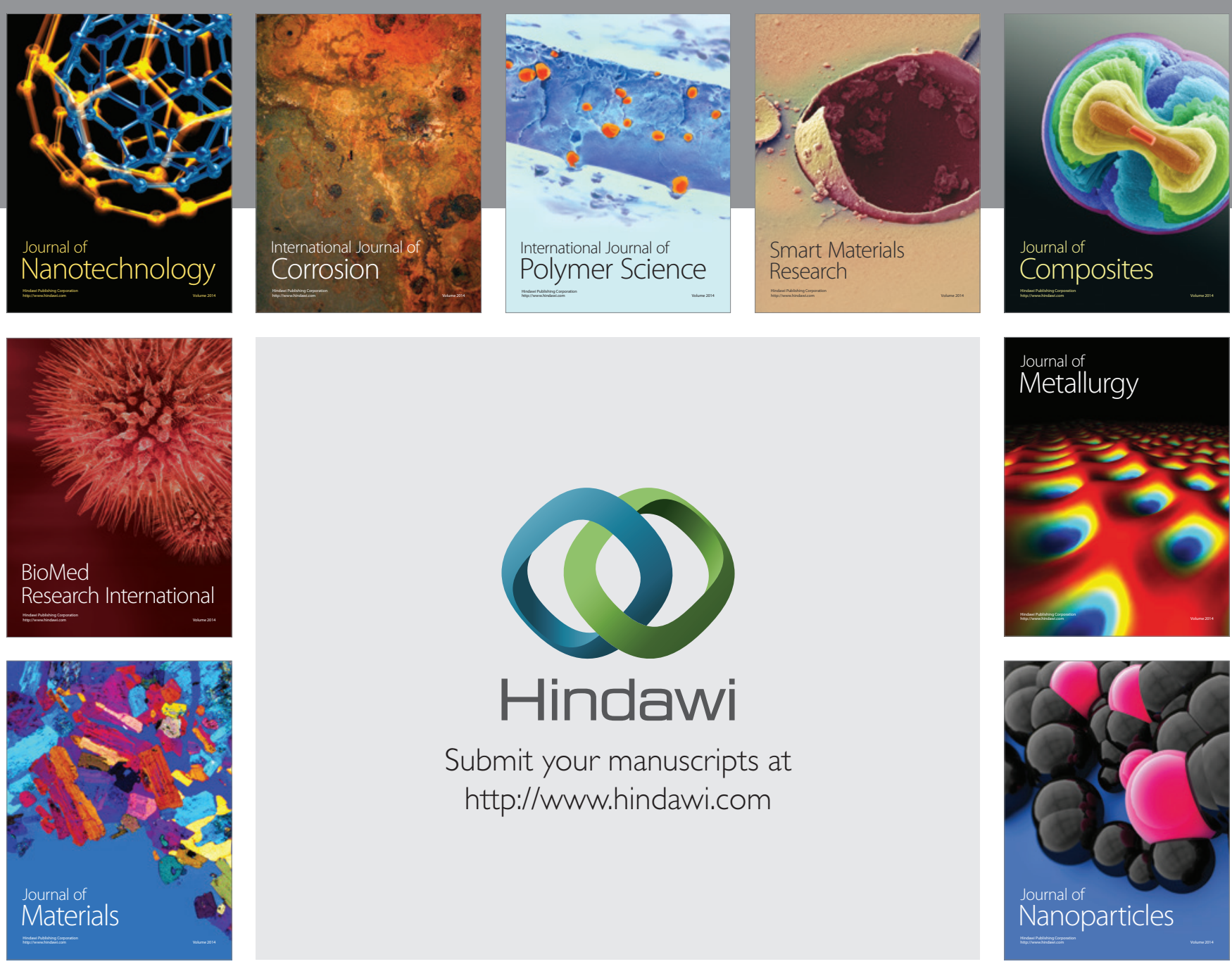

Submit your manuscripts at http://www.hindawi.com
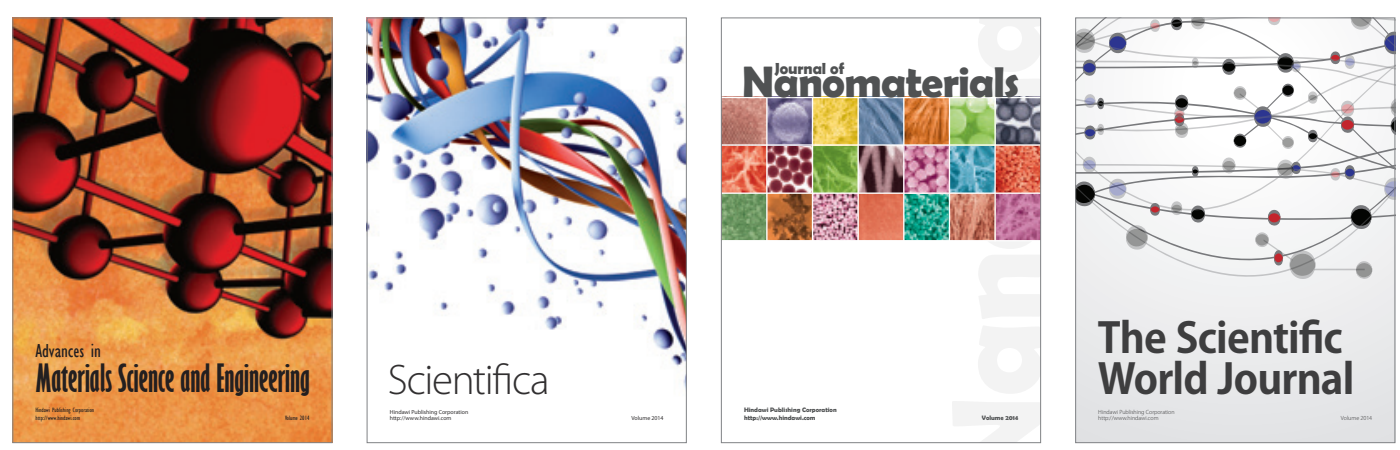

\section{The Scientific World Journal}
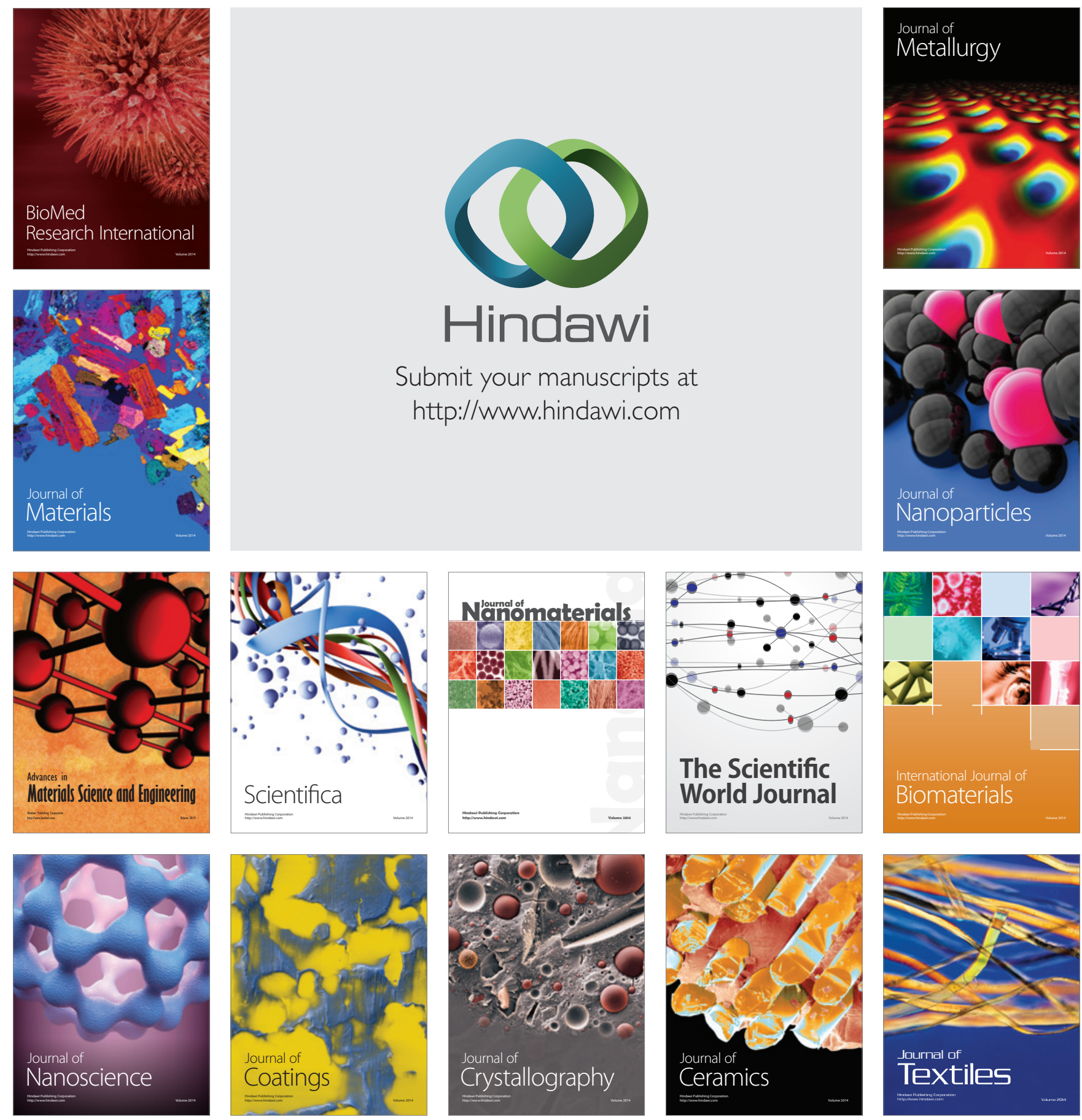